Check for updates

Cite this: Nanoscale Adv., 2019, 1, 3252

\title{
ZnO decorated laser-induced graphene produced by direct laser scribing $\dagger$
}

\author{
Joana Rodrigues, (D) * Julia Zanoni, Guilherme Gaspar, (D) António J. S. Fernandes, \\ Alexandre F. Carvalho, (D) Nuno F. Santos, (D) Teresa Monteiro (D) \\ and Florinda M. Costa
}

A scalable laser scribing approach to produce zinc oxide $(\mathrm{ZnO})$ decorated laser-induced graphene (LIG) in a unique laser-processing step was developed by irradiating a polyimide sheet covered with a $\mathrm{Zn} / \mathrm{ZnO}$ precursor with a $\mathrm{CO}_{2}$ laser $(10.6 \mu \mathrm{m})$ under ambient conditions. The laser scribing parameters revealed a strong impact on the surface morphology of the formed LIG, on ZnO microparticles' formation and distribution, as well as on the physical properties of the fashioned composites. The ZnO microparticles were seen to be randomly distributed along the LIG surface, with the amount and dimensions depending on the used laser processing conditions. Besides the synthesis conditions, the use of different precursors also resulted in distinct $\mathrm{ZnO}$ growth's yields and morphologies. Raman spectroscopy revealed the existence of both wurtzite- $\mathrm{ZnO}$ and $\mathrm{sp}^{2}$ carbon in the majority of the produced samples. Broad emission bands in the visible range and the typical $\mathrm{ZnO}$ near band edge (NBE) emission were detected by photoluminescence studies. The spectral shape of the luminescence signal was seen to be extremely sensitive to the employed processing parameters and precursors, highlighting their influence on the composites' optical defect distribution. The sample produced from the $\mathrm{ZnO}$-based precursor evidenced the highest luminescence signal, with a dominant NBE recombination. Electrochemical measurements pointed to the existence of charge transfer processes between LIG and the $\mathrm{ZnO}$ particles.

Received 13th December 2018

Accepted 12th July 2019

DOI: 10.1039/c8na00391b

rsc.li/nanoscale-advances

\section{Introduction}

Zinc oxide $(\mathrm{ZnO})$ is considered one of the most explored and versatile semiconductor oxide materials in terms of its physical/ chemical properties, namely the high surface-area provided by the myriad of morphologies produced at the nano/micro scale level, high crystallinity, nontoxicity, biological compatibility, and improved optical, electrical and electrochemical response. All these features make ZnO structures highly desirable for various applications including optics, optoelectronics, supercapacitors, biosensors, tissue engineering or drug delivery systems, among others. ${ }^{1-5}$

The development of $\mathrm{ZnO}$ composites with other materials is expected to combine the properties of both components, allowing the production of functional materials with more advantageous properties than each component by itself. ${ }^{6,7}$ Amongst these composite structures, an interesting class of nanostructured carbon-based forms (e.g. graphene, carbon nanotubes-CNTs) have been employed in the fabrication of a wide range of applications, as for instance in biosensors,

Departamento de Física \& I3N, Universidade de Aveiro, Campus Universitário de Santiago, 3810-193 Aveiro, Portugal. E-mail: joana.catarina@ua.pt; Tel: +351 234247261

$\dagger$ Electronic supplementary information (ESI) available. See DOI: $10.1039 / \mathrm{c} 8 \mathrm{na00391b}$ photovoltaics, supercapacitors or photocatalysts. ${ }^{8-16}$ Previous works by our research group ${ }^{17,18}$ already explored the synergistic properties of $\mathrm{ZnO}$ with carbon-based materials. Specifically, an enhancement of the $\mathrm{ZnO}$ photoluminescence (PL) was identified when nanostructures of this semiconductor were deposited on a forest of vertically-aligned CNTs (VACNTs), ${ }^{17}$ while $\mathrm{ZnO} /$ CNT buckypaper composites were seen to maintain the strong luminescent properties of the $\mathrm{ZnO}$ structures, exhibiting the electrical properties associated with the CNTs. ${ }^{18}$ Furthermore, an enhancement of the physical properties of $\mathrm{ZnO}$ and carbonbased materials when brought together has also been reported, showing interesting advantages, namely in sensing applications. ${ }^{19-23}$ For instance, Lupan et al. ${ }^{19}$ recently described the influence on ultraviolet (UV) and gas sensing properties of $\mathrm{ZnO}$ nanowires after combining them with CNTs. These authors observed that the addition of CNTs to the porous ZnO networks led to an enhancement of the sensing properties of $\mathrm{ZnO}$, with an efficient detection of different gases, especially in the case of ammonia. Fullerene $\mathrm{C}_{60}$ hybridized $\mathrm{ZnO}$ tetrapods were also employed in the fabrication of gas sensing devices, revealing interesting sensing behaviour towards volatile organic compounds. ${ }^{24}$ Besides gas sensing, $\mathrm{ZnO} /$ carbon composites have been also used in biosensing applications for the detection of several biospecies, such as glucose, ${ }^{20,25} \mathrm{DNA}^{26}$ or cancer indicators. ${ }^{21,27}$ For example, a device for detection of prostate- 
specific antigen (PSA) was accomplished using ZnO quantum dots/CNTs composites, abling the sensor to detect PSA concentration in serum samples as low as $0.61 \mathrm{pg} \mathrm{ml}^{-1} .^{27}$ Moreover, Zhao et al. ${ }^{20}$ reported the fabrication of a glucose sensor based on ZnO-nanorods/graphene heterostructures, which showed a linear response to glucose concentrations in the range of $0.2-1.6 \mathrm{mM}^{20} \mathrm{~A}$ common feature in the different $\mathrm{ZnO} /$ carbon composites reported in the literature is the need of several steps to produce the materials that comprise the composite and the composite itself. Usually, both components are produced separately, with the desired dimensions and morphologies, and then mixed together to form the final material. ${ }^{15,19,28}$ Frequently, this approach involves surface modification of one or both constituents to establish covalent, noncovalent or electrostatic interactions between them, ${ }^{29,30}$ resulting in elaborated and time consuming processes. Another approach involves the synthesis of $\mathrm{ZnO}$ in the presence of the previously prepared carbon material, onto which the oxide semiconductor grows with the chosen morphology. ${ }^{16,17,29}$ This approach is less time consuming and promotes a closer link between both components, since the $\mathrm{ZnO}$ grows directly on the carbon-based substrate. Even so, a multi-step preparation is required to reach the desired composite. Aiming at simplifying these processes, in the present work we report on the production of ZnO decorated laser-induced graphene (LIG) in the same laser-processing step. In this process, a $\mathrm{CO}_{2}$ laser irradiates a $\mathrm{Zn} / \mathrm{ZnO}$-based layer covering a polyimide $-\mathrm{C}_{22} \mathrm{H}_{10} \mathrm{O}_{5} \mathrm{~N}_{2}$ (Kapton ${ }^{\circledR}$ ) sheet used as precursors for $\mathrm{ZnO}$ and LIG, respectively. The production of LIG from Kapton ${ }^{\circledR}$ by laser scribing using a $\mathrm{CO}_{2}$ laser was firstly reported by the group of Tour. ${ }^{31}$ Its formation by graphenisation is believed to be induced by the high localised temperatures (higher than $2500{ }^{\circ} \mathrm{C}$ according to laser-induced fluorescence) attained by a highly focused laser beam, giving rise to a photothermal carbonisation process. ${ }^{31}$ Additionally, some attempts have been made to improve the specific capacitance of LIG-based electrodes ${ }^{32}$ by forming composites with other materials, as is the case of $\mathrm{MoS}_{2}{ }^{33}$ and metal oxides as $\mathrm{Co}_{3} \mathrm{O}_{4}, \mathrm{MoO}_{2}$, and $\mathrm{Fe}_{3} \mathrm{O}_{4},{ }^{34}$ mostly by embedding the metal-complexes used as precursors for the metal oxide particles in the polyimide film during the polymer preparation. Laser induction is then conducted on this metal-complexcontaining polyimide substrate to form the composites. ${ }^{34}$

Following the work of Lin et al. ${ }^{31}$ several others have been reported regarding the development, optimisation and application of LIG. ${ }^{32,35-46}$ In fact, the production of LIG by such scribing process has now been accomplished using other carbon sources besides the polyimide, as for instance cloth, paper or even food, ${ }^{41,43,47}$ as well as other laser wavelengths. ${ }^{48}$ Moreover, its application extend from microfluidic devices, sensors, optoelectronic devices, microsupercapacitors, to catalysts, among others..$^{40,41,43,45,46,49}$

When compared to other techniques, the method in focus by the present report possesses key advantages. Among these, we highlight the prompt synthesis process of the composites, the ability to perform a pattern with the computer-controlled laserscribing system, the production of flexible composite's samples and its easy scalability in a time- and cost-effective way.
Moreover, since the formation of LIG and ZnO takes place simultaneously, a stronger link and interaction between the two materials is expected when compared with other approaches.

The main goal of the present work is to develop these nanostructured composites, aiming to use them as transducer elements to be further incorporated into affordable, flexible and disposable biosensors. Nevertheless, before testing the new composites on the foreseen application, an adequate knowledge of their fundamental properties is of paramount importance to understand the materials potentialities and also to be able to control/tune the desired features.

\section{Experimental details}

\subsection{Materials synthesis}

A continuous wave (CW) $\mathrm{CO}_{2}$ laser (Redsail M500) with a wavelength of $10.6 \mu \mathrm{m}$ (maximum power output of $50 \mathrm{~W}$ and a beam diameter in the order of $\sim 100 \mu \mathrm{m}$ ) was used to produce the $\mathrm{ZnO}$ decorated LIG composites (hereafter designated by ZnO/LIG). This system is fitted with a mechanically driven $X-Y$ focusing head. Fig. 1 depicts a schematic representation of all steps involved in the preparation of the precursor materials and the synthesis process. The $\mathrm{ZnO} / \mathrm{LIG}$ samples were formed by laser irradiation of a Kapton ${ }^{\circledR}$ sheet (HN500), previously covered with metallic $\mathrm{Zn} / \mathrm{ZnO}$ powders embedded in a paste. This paste was used in order to promote a good adhesion of the $\mathrm{Zn} / \mathrm{ZnO}$ powder to the Kapton ${ }^{\circledR}$ sheet, thus avoiding the loss of this precursor during the laser scribing process. Therefore, the Kapton ${ }^{\circledR}$ will act as the precursor for LIG, while the $\mathrm{Zn} / \mathrm{ZnO}$-based paste is the precursor for ZnO. This paste was spread onto the Kapton ${ }^{\circledR}$ sheet by dropping $1 \mathrm{ml}$ in a defined area of $\sim 4 \times 4 \mathrm{~cm}^{2}$, delimited with a scotch tape, as illustrated in Fig. 1. Different organic ligands were tested to evaluate the best approach in forming a homogeneous cover of the Kapton ${ }^{\circledR}$ surface by the precursor. First, a mixture of Zn (Sigma-Aldrich, purum) powder with polyvinyl alcohol (PVA) dispersed in water (with a concentration of $0.1 \mathrm{~g} \mathrm{ml}^{-1}$ ) was tested and $1 \mathrm{~g}$ of the commercial $\mathrm{Zn}$ powder was added to $10 \mathrm{ml}$ of PVA. This mixture was stirred for $1 \mathrm{~h}$, followed by ultrasonic bath with the same duration, aiming to obtain a fairly homogeneous paste. The Kapton ${ }^{\circledR}$ sheet was then covered with this paste via doctor blade technique, and then left to dry in air. During the drying process, it was observed that the Zn/PVA paste (hereafter designated by $\mathrm{Zn \# 1)}$ tends to accumulate more on the borders delimited by the tape. The average thickness of the $\mathrm{Zn \# 1}$ layer was found to be $\sim 6.7 \mu \mathrm{m}$, as shown in Fig. S1a. $\dagger$ However, this layer is rather inhomogeneous, as highlighted in Fig. S1b, $\dagger$ with some large Zn agglomerates, as well as nearly Znfree areas. Moreover, when left to dry, the high plasticity of this layer led to its detachment from the polymer sheet in some regions (see Fig. S2 $\dagger$ ), compromising the laser writing process in such areas.

To overcome these drawbacks, a new Zn-based precursor paste was prepared in order to obtain a higher homogeneity in the preparation of the $\mathrm{Zn} /$ Kapton precursors, and subsequently in the $\mathrm{ZnO} / \mathrm{LIG}$ composites. In this case, the $\mathrm{Zn}$ commercial powders were placed in a planetary ball mill during $1 \mathrm{~h}$ at 

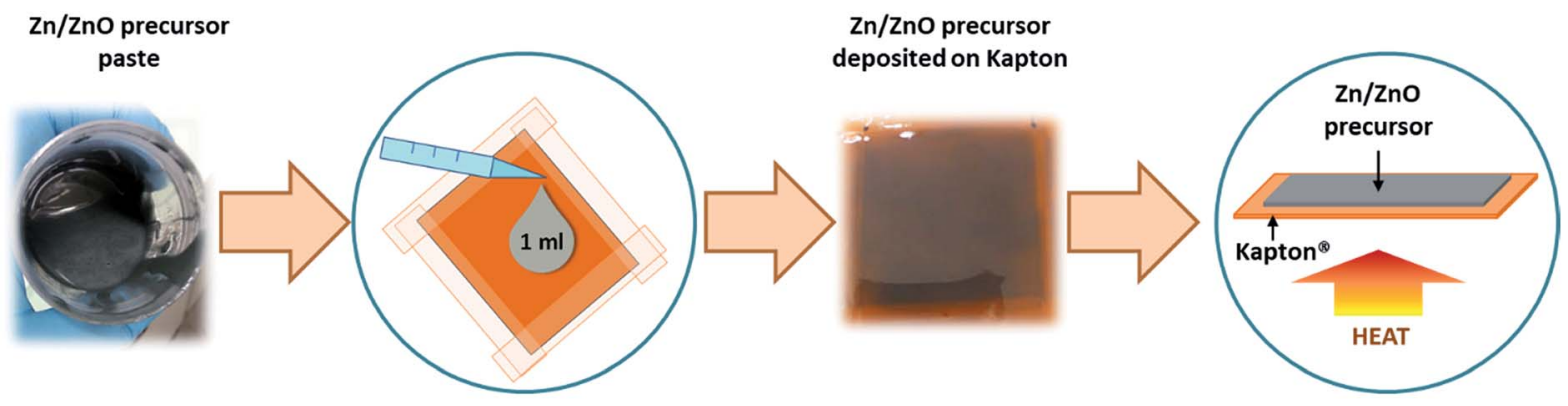

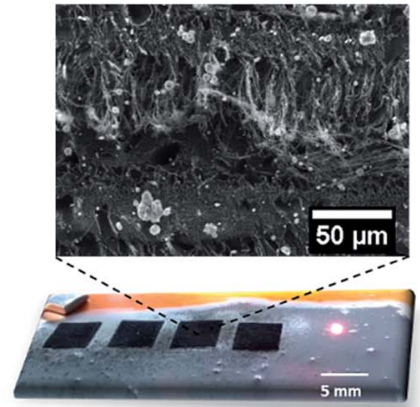

ZnO/LIG composite
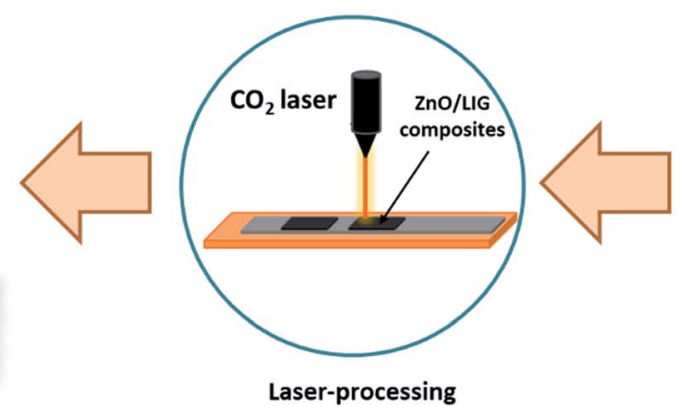

Laser-processing

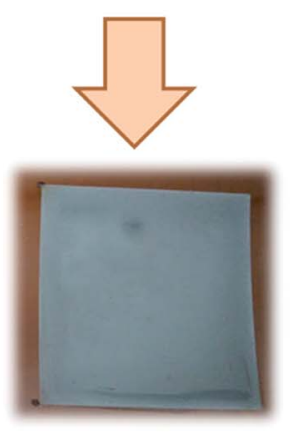

Zn/Zno precursor on Kapton after heat treatment

Fig. 1 Schematic representation of all steps involved in the preparation of $\mathrm{Zn} / \mathrm{ZnO}$-covered polyimide sheet used as precursor and the laserscribing process to form the ZnO/LIG composites. A representative SEM micrograph (processing conditions: $P \sim 24 \mathrm{~W}, v=200 \mathrm{~mm} \mathrm{~s} \mathrm{~s}^{-1}$ and $d=$ $0.075 \mathrm{~mm}$, focused conditions - set\#1) was included to show the LIG structure with the presence of small ZnO particles randomly dispersed onto the surface.

$500 \mathrm{rpm}$ to reduce the particle dimension and their size distribution. The milled powders $(1 \mathrm{~g})$ were then mixed with ethanol ( $2 \mathrm{ml})$, terpineol ( $4 \mathrm{~g}$, Sigma-Aldrich) and ethyl cellulose ( $0.5 \mathrm{~g}$, Sigma-Aldrich) to form a viscous paste (hereafter desig-

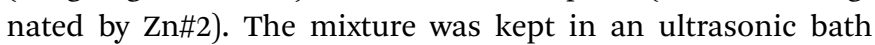
during $1 \mathrm{~h}$ and another 30 min under magnetic stirring. This procedure was repeated to inssure a homogeneous paste. The new precursor layer was then spread onto the Kapton ${ }^{\circledR}$ surface using the same method employed for the $\mathrm{Zn \# 1}$ paste. However, in this case, an additional heating step to dry the paste was included, instead of letting the samples to dry in air. This heating step was conducted at $100{ }^{\circ} \mathrm{C}$ during $\sim 1 \mathrm{~h}$. With this step, a more uniform cover of the polymer surface was obtained.

Table 1 Summary of the synthesis conditions employed in the different sets of tests

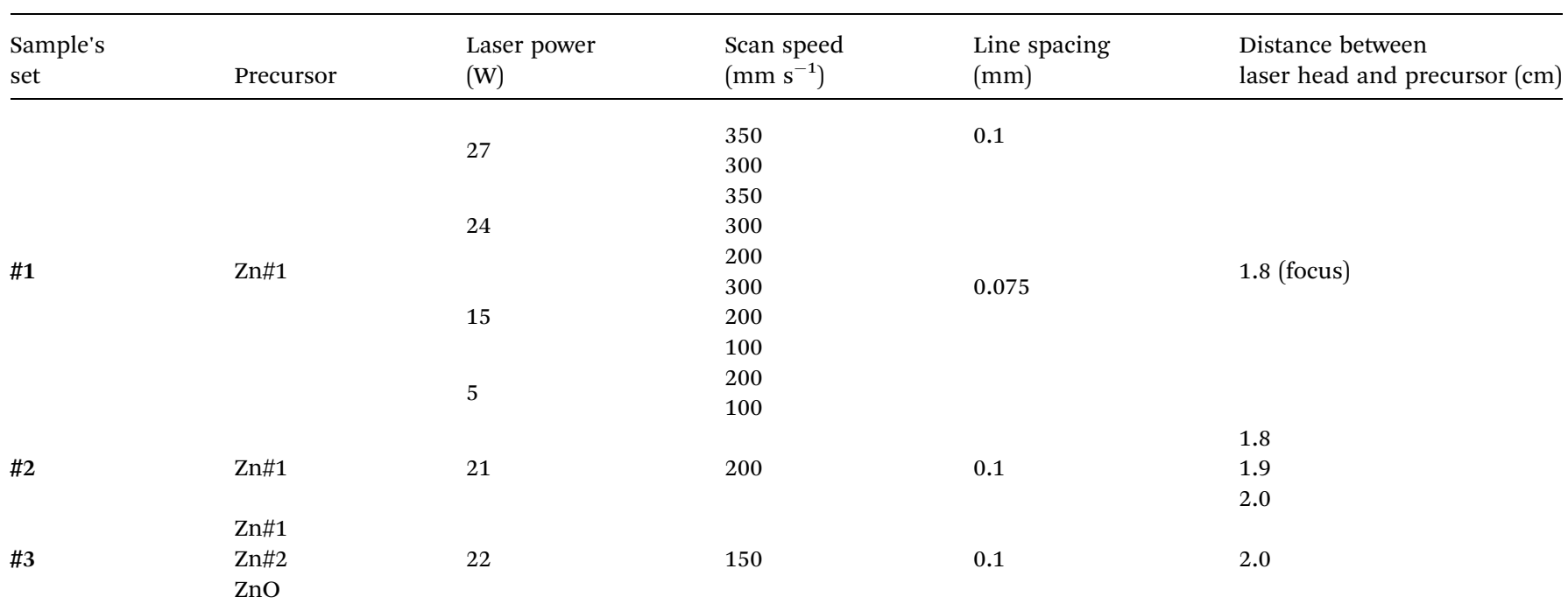


Additionally, another paste was prepared in the same way

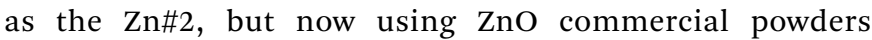
(AnalaR, 99.7\%) instead of the $\mathrm{Zn}$ ones. In this case, the average thickness of the layer was found to be $\sim 16 \mu \mathrm{m}$ (Fig. S1c $\dagger$ ) and with an improved homogeneity when compared with the Zn\#1 paste (Fig. S1d †). It is worth to note that a similar thickness was also found for the $\mathrm{Zn \# 2}$ precursor paste.

A combination of different laser parameters was employed with focus on scan speed $v\left(100-350 \mathrm{~mm} \mathrm{~s}^{-1}\right)$, laser power output $P(\sim 15.0-27 \mathrm{~W})$ and distance between the laser head and the substrate $d_{\text {laser }}(1.8-2.4 \mathrm{~cm})$. Focused conditions corresponde to $d_{\text {laser }}=1.8 \mathrm{~cm}$. The distance between scanning lines $d$ was kept between 0.075 and $0.1 \mathrm{~mm}$. The parameters were chosen to enable the synthesis of both LIG and ZnO while preventing the full polymer degradation by always keeping a thin unaffected Kapton ${ }^{\circledR}$ layer that provides the flexible mechanical support. Mainly, three sets of samples were considered to evaluate the influence of the different processing parameters and precursors on the properties of the composites, as summarized in Table 1. All samples were produced under ambient conditions. After their synthesis, all samples were washed with distilled water to remove the $\mathrm{ZnO}$ particles not attached to LIG.

\subsection{Morphological, structural, optical and electrochemical characterisation}

The morphology of the produced samples was studied by scanning electron microscopy (SEM) using a TESCAN Vega3 SBH SEM microscope. Energy-dispersive X-ray spectroscopy (EDS) maps were acquired using a Bruker Xflash 410 M Silicon Drift Detector, with a $133 \mathrm{eV}$ energy resolution (at $\mathrm{MnK}_{\alpha}$ ) @ $100 \mathrm{k}$ cps.

$3 \mathrm{D}$ reconstruction of the samples surface morphology was obtained from a $\mathrm{S}$ neox non-contact optical profiler from Sensofar Metrology. The instrument was operated under confocal mode, allowing measurements of smooth to rough surfaces with variable resolution, according to the microscope's objective. Three different objective magnifications were used in the present work, namely $10 \times, 20 \times$ and $50 \times$, resulting in lateral resolutions of $1.29,0.65$ and $0.26 \mu \mathrm{m}$ and vertical resolutions of 25,8 and $3 \mathrm{~nm}$, respectively. Subsequent image reconstruction and morphology profiles were assessed through SensoScan 6.2 software.

Micro-Raman spectroscopy measurements were obtained in a Horiba Jobin Yvon HR800 instrument in backscattering configuration by exciting the materials with a $442 \mathrm{~nm}$ line from a CW He-Cd laser (Kimmon IK Series), using a ND 0.6 neutral density filter and focusing with an objective of $50 \times$ magnification and numerical aperture of 0.7 . The spectra were acquired in the range between 150 and $3300 \mathrm{~cm}^{-1}$.

Room temperature (RT) steady-state PL measurements were performed using the $325 \mathrm{~nm}(3.81 \mathrm{eV})$ line from a CW He-Cd laser (Kimmon IK Series) with a beam spot of $\sim 1 \mathrm{~mm}$ and an excitation power density below $0.6 \mathrm{~W} \mathrm{~cm}^{-2}$. The experiments were carried out under a $90^{\circ}$ geometry. The luminescence was measured using a dispersive system SPEX 1704 monochromator ( $1 \mathrm{~m}, 1200 \mathrm{gr} \mathrm{mm}^{-1}$ ) fitted with a water-cooled Hamamatsu R928 photomultiplier tube. All samples were investigated under the same excitation/detection conditions and the signal was maximised at the visible band maximum. As stated in the Introduction section, the main goal is to combine optical and electrochemical transduction in a single device, thus the luminescence outcome of the produced composites was chosen as the main criteria to be monitored for the optimisation of the processing conditions. The samples that resulted in composites with no RT measurable luminescence emission were discarded.

Electrochemical characterisation was accomplished by cyclic voltammetry (CV) and electrochemical impedance spectroscopy (EIS) via a Versastat 3 instrument. The CV and EIS response of the $\mathrm{ZnO} / \mathrm{LIG}$ composites (from $\mathrm{ZnO}$-based precursor) were measured and compared to LIG reference samples (same processing conditions as the composite samples). Measurements were performed in duplicate, using a $\mathrm{Ag} / \mathrm{AgCl}(1 \mathrm{M} \mathrm{KCl})$ reference electrode and a platinum wire counter electrode in $\mathrm{N}_{2}$ bubbled $10 \mathrm{mM}$ phosphate buffer saline (PBS pH 7.4, from Fisher BioReagents) solutions. The ferro/ferricyanide redox couple was employed for faradaic measurements.

\section{Results and discussion}

\subsection{Microscopical analyses}

In order to obtain the desired $\mathrm{ZnO} / \mathrm{LIG}$ composites, several laser-writing conditions and $\mathrm{ZnO}$ precursors were tested . At the first stage (set\#1), the main goal was to use a wider range of parameters to assess the general tendency of their influence on the composites synthesis. For this purpose, the $\mathrm{Zn \# 1}$ precursor was employed and the synthesis was performed at focused conditions $\left(d_{\text {laser }}=1.8 \mathrm{~cm}\right)$, as described in the experimental section. Moreover, LIG reference samples were also produced with the same processing parameters as the composite ones. It was verified that the threshold conditions for the composite formation were different from those required for LIG production, especially regarding the applied laser powers. Due to the Zn/PVA paste covering Kapton ${ }^{\circledR}$, higher laser powers were needed to form the $\mathrm{ZnO} / \mathrm{LIG}$ structures. Indeed, when only the polymer is present, powers of $\sim 5 \mathrm{~W}$ have shown to be enough to start the graphenisation process (even for scanning speeds of $350 \mathrm{~mm} \mathrm{~s}^{-1}$ ), in line with what was reported by other authors. ${ }^{31,35}$ On the other hand, when the Zn-based precursor is present, a higher threshold power in the range of $\sim 10-15 \mathrm{~W}$ was necessary to initiate the composite formation, since lower powers were not enough to promote the photothermal carbonisation of the Kapton ${ }^{\circledR}$ sheet. This can be explained by photon absorption and/or dissipation by the Zn/PVA paste and partial reflection of the incident photons on the metallic $\mathrm{Zn}$ particles. Both effects lead to an attenuation of the laser power that reaches the polymer, with a consequent reduction of the attained local temperature for similar applied powers.

Fig. 2 shows SEM micrographs of selected $\mathrm{ZnO} / \mathrm{LIG}$ composites prepared in set\#1. As it can be seen, the choice of laser-writing parameters has a significant effect on the formed structures. Although in the studied cases it was possible to 


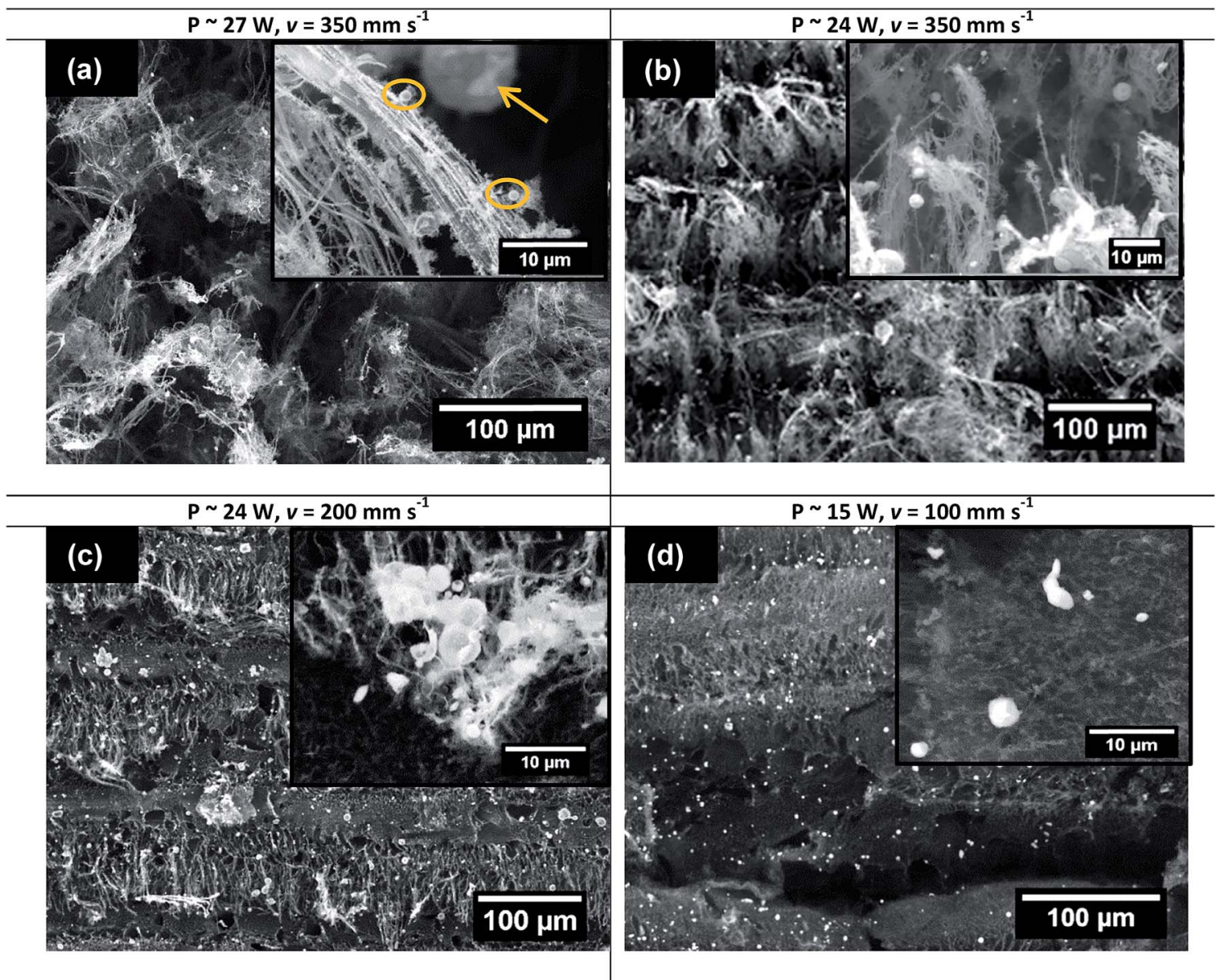

Fig. 2 SEM micrographs of the $\mathrm{ZnO} / \mathrm{LIG}$ composites with different laser processing conditions from set\#1. The yellow circles and arrow highlight the presence of $\mathrm{ZnO}$ particles with different sizes. (a) $P \sim 27 \mathrm{~W}, v=350 \mathrm{~mm} \mathrm{~s}^{-1}$; (b) $P \sim 24 \mathrm{~W}, v=350 \mathrm{~mm} \mathrm{~s}^{-1}$; (c) $P \sim 24 \mathrm{~W}, v=200 \mathrm{~mm} \mathrm{~s}^{-1}$; and (d) $P \sim 15 \mathrm{~W}, v=100 \mathrm{~mm} \mathrm{~s}^{-1}$.

observe that the laser irradiated region led to the formation of a carbon-based material that protrudes from the Kapton ${ }^{\circledR}$ substrate, distinct features arise from the different parameters combination. For instance, it was observed that higher laser powers (up to $\sim 27 \mathrm{~W}$ ) promote the formation of a large amount of randomly oriented carbon fibres (Fig. 2a and b). Nonetheless, it was seen that the occurrence of these fibres could be controlled by an adequate combination of laser power and scanning speed. A comparison between images (a) and (b) and then between (b) and (c) of Fig. 2 allows to clearly identify that, while keeping the same line spacing, a reduction of the laser power leads to a reduction of the size/amount of the carbon fibres for the same scan rate $\left(350 \mathrm{~mm} \mathrm{~s}^{-1}\right)$. In a similar way, and for the same applied power $(\sim 24 \mathrm{~W})$, the amount of fibres was reduced by decreasing the scan speed from $350 \mathrm{~mm} \mathrm{~s}^{-1}$ to $200 \mathrm{~mm} \mathrm{~s}^{-1}$. As expected, these two parameters were seen to be deeply correlated, given that as the laser power increases, higher scan rates are also required to avoid partial or full degradation of the polymer sheet. Thus, an adequate tuning of the synthesis parameters enables the promotion of different surface morphologies in the produced carbon-based materials. Recently, Duy et al. ${ }^{42}$ reported a detailed work regarding the formation of these laser-induced graphene fibres (LIGF). They consider several scribing parameters in the formation of such fibres, namely the wavelength of the used laser, fluence and laser image density (dots per length unit), which determines the overlap of subsequent laser pulses used to form the image. Overlapping was found crucial to suppress the formation of the fibres. In our setup, this superposition can be determined by the laser scanned lines distance and laser power. An increase in power broadens the spot above the graphenisation threshold. Thus, the regions with a higher amount of fibres correspond to a lower overlap of the laser path.

By adjusting the processing parameters in order to reduce the formation of these carbon fibres, a 3D foam-like LIG structure was visible (Fig. $2 \mathrm{c}$ and d). This foam exhibits large pores with an irregular shape and diameters in the range of one to a few tens of micrometres, which are attributed to the rapid liberation of gases produced during the photothermal process. ${ }^{31,35}$ Besides the large-size pores, LIG also displays a porous structure with much smaller pores' diameters (microns to sub micrometres) than the previous ones (Fig. 2d). According to Luo et al., ${ }^{35}$ these porous regions are also due to the release of the mentioned pyrolysis gases, being more 
pronounced as the laser power increases, resulting in higher thicknesses and heights. In fact, in a typical polyimide carbonisation process, two main steps are present: pyrolysis and carbonisation itself. ${ }^{\mathbf{5 0 , 5 1}}$ In the first step, which occurs between 500-650 ${ }^{\circ} \mathrm{C}$, there is a breakage of the carbonyl groups in the imide part, leading to an abrupt release of $\mathrm{CO}$ and $\mathrm{CO}_{2}$ gases, accompanied by a pronounced weight loss of the polymer. In the second step, which occurs over a temperature range from $800{ }^{\circ} \mathrm{C}$ to more than $1000{ }^{\circ} \mathrm{C}$ (for a Kapton ${ }^{\circledR}$ substrate only), mostly $\mathrm{H}_{2}$ is released. ${ }^{\mathbf{5 0 , 5 1}}$ After the release of these molecules, the aromatic compounds can be rearranged to form few-layer graphene nanostructures.. ${ }^{\mathbf{3 1} 32}$ This pyrolysis/carbonisation proceeds at a very fast rate due to the rapid laser heating inherent to the laser-writing process. ${ }^{35}$

Additionally, it was also observed that with the increase of the scan speed ( $>350 \mathrm{~mm} \mathrm{~s}^{-1}$ ) the uniformity of the samples was reduced, showing alternating regions of high and low porosity, likely to be due to the non-uniform exposition of the precursors to the laser.

Simultaneously with the LIG formation, the production of randomly distributed spherical-shaped particles also takes place on LIG's surface, depicting a wide range of micrometrescale sizes. EDS mapping revealed their correspondence to $\mathrm{ZnO}$ (Fig. 3), which was further corroborated by Raman measurements (section 3.2). A closer inspection of the SEM images (insets in Fig. 2 and 3) showed that the larger microparticles are in fact comprised by aggregates of much smaller ones, especially when higher laser powers are applied. Scrutinising the sample produced with the highest power employed in this study ( $\sim 27 \mathrm{~W}$ - Fig. 2a), it was evident that, besides the large aggregates of microparticles (diameters in the range of a few micrometers - arrow in inset of Fig. 2a and S3a †), smaller particles can be found along with the carbon fibres (e.g., circles in the inset of Fig. 2a). On the other hand, in the case of the sample synthesised with $\sim 15 \mathrm{~W}$ (lowest applied power for the composites' formation), the $\mathrm{ZnO}$ aggregates tend to be scarcer, the particles are smaller and with a more irregular shape, as highlighted in the inset of Fig. 2 d. This can be attributed to the lower temperature expected for such powers, since the formation of these $\mathrm{ZnO}$ microparticles is promoted by the thermal oxidation of the $\mathrm{Zn}$ powder in air. The local heating induced by the $\mathrm{CO}_{2}$ laser beam leads to the $\mathrm{Zn}$ transformation into $\mathrm{ZnO}$, as the temperatures attained in this process are much higher than the melting point of bulk metallic $\mathrm{Zn}\left(420{ }^{\circ} \mathrm{C}^{52}\right)$. Therefore, one can assume that partial melting followed by evaporation of Zn should occur during the laser-writing process. The reaction with oxygen (present in the surrounding atmosphere) with the outer surface of the previously formed $\mathrm{Zn}$ droplets originates the $\mathrm{ZnO}$ nuclei from which the particles start to grow. ${ }^{53}$ Thus, $\mathrm{Zn}$ acts as both reactant and catalyst for the $\mathrm{ZnO}$ growth, as reported by other authors. ${ }^{54}$ For a constant oxygen content, the size of the $\mathrm{ZnO}$ structures is strongly dependent on the local temperature and $\mathrm{Zn}$ partial vapour pressure. Both high temperature and high $\mathrm{Zn}$ availability lead to a rapid growth into large structures, whereas the opposite results in slow nucleation/growth rates. ${ }^{55}$ It may explain why less and smaller microparticles/aggregates are observed in the case of the samples processed at $\sim 15 \mathrm{~W}$. A lower scan rate is expected to enable a higher exposure of the $\mathrm{Zn}$ precursor to the laser beam (heating source), providing more energy (at a fixed laser power) to initiate the $\mathrm{ZnO}$ nucleation and growth, and possibly leading to the production of a higher amount of $\mathrm{ZnO}$ particles. Since this $\mathrm{Zn}$ precursor is comprised by a dispersion of the metal particles in PVA, it is also worth to mention that, at such temperatures, the organic material is expected to fully decompose during the laser processing (two stage decomposition at $\sim 240{ }^{\circ} \mathrm{C}$ and $450{ }^{\circ} \mathrm{C}^{56,57}$ ), being absent from the laserprocessed areas.

Finally, another aspect to take into account in the composite formation is the gas liberation during the graphenisation process. It is expected that the outgassing during carbonisation of LIG may spread to the newly formed $\mathrm{ZnO}$ particles and remaining metallic $\mathrm{Zn}$ to the peripheral areas that will be further irradiated. The interaction of these gases with the particles under formation can be responsible for the presence of different chemical groups at the $\mathrm{ZnO}$ surface, which may give rise to distinct optical properties, as will be discussed later on. Furthermore, the way the gases are released (depending on the
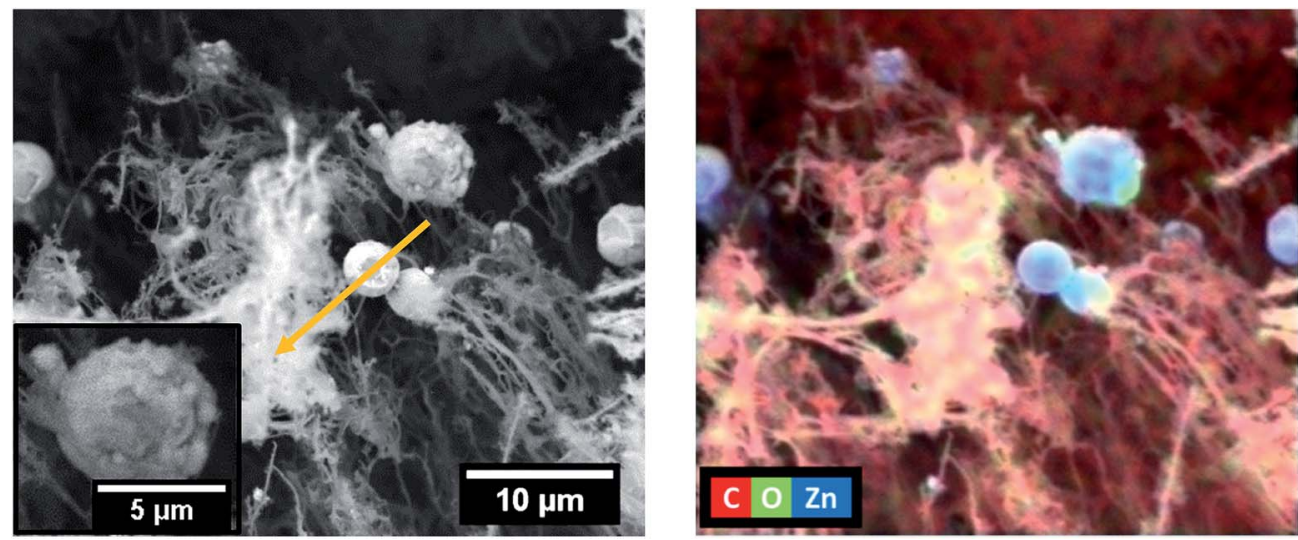

Fig. 3 SEM image of a sample produced with $\sim 24 \mathrm{~W}, v=350 \mathrm{~mm} \mathrm{~s}^{-1}, d=0.075 \mathrm{~mm}$ and focused conditions (left) and EDS mapping of the correspondent region (right). 
applied scribing conditions) may also influence how the $\mathrm{ZnO}$ particles are distributed on the LIG surface. For example, the quick "bombing" effect (as denominated by Luo et al. ${ }^{35}$ ) experienced by applying high laser powers may contribute to the "expulsion" of some ZnO particles out of the surface of LIG. When the $\mathrm{ZnO} / \mathrm{LIG}$ composites samples are compared to the ones only containing LIG, one should bear in mind that the precursor layer/paste is likely to absorb/retain part of the formed gases, which will change the local environment at the polymer surface and therefore contribute to the differences observed in the topographic/morphological structures.

Considering now the influence of the focus conditions, it was verified that increasing the distance between the laser head and the precursor (set\#2) to $2 \mathrm{~cm}$, which corresponds to slightly defocused conditions, results in the formation of a composite with better luminescent properties (see section 3.3), namely higher PL intensity and, consequently, higher signal to noise ratio. Moreover, comparing samples prepared with the same scan speed and similar laser powers (Fig. 2c and 4 top left), one clearly sees a further reduction of the carbon fibres formation, as well as a more uniform surface morphology and porosity of
LIG. A likely explanation for this noticeable change is related with the increase in the laser beam spot and more homogeneous radial distribution of the power. As reported by Chyan et al. ${ }^{47}$ this will result in multiple lasing at a given location for the same processing speed and in one single laser pass, which leads to a less fibrous morphology and to a more sheet-like structure of LIG. It is worth to mention that for values of $d_{\text {laser }}$ $>2.2 \mathrm{~cm}$ no composites could be formed. Regarding the $\mathrm{ZnO}$ formation itself, no significant changes were identified for the amount, shape and size of the microparticles. Therefore, the results suggest that using defocused conditions may promote an enhancement in the crystallinity of the formed $\mathrm{ZnO}$ (see Raman section), but not in their production yield. Similarly to what was discussed in the case of the scan speed, laser beam defocusing results in a longer and milder exposure of the $\mathrm{Zn}$ precursor and the formed $\mathrm{ZnO}$ particles to the beam for the same processing time, thus leading to better structural and optical properties.

Changing the precursor from Zn\#1 to Zn\#2 (Fig. 4 top left and right, respectively), and focusing on samples from set\#3, results in changes in the surface morphology of the composites,

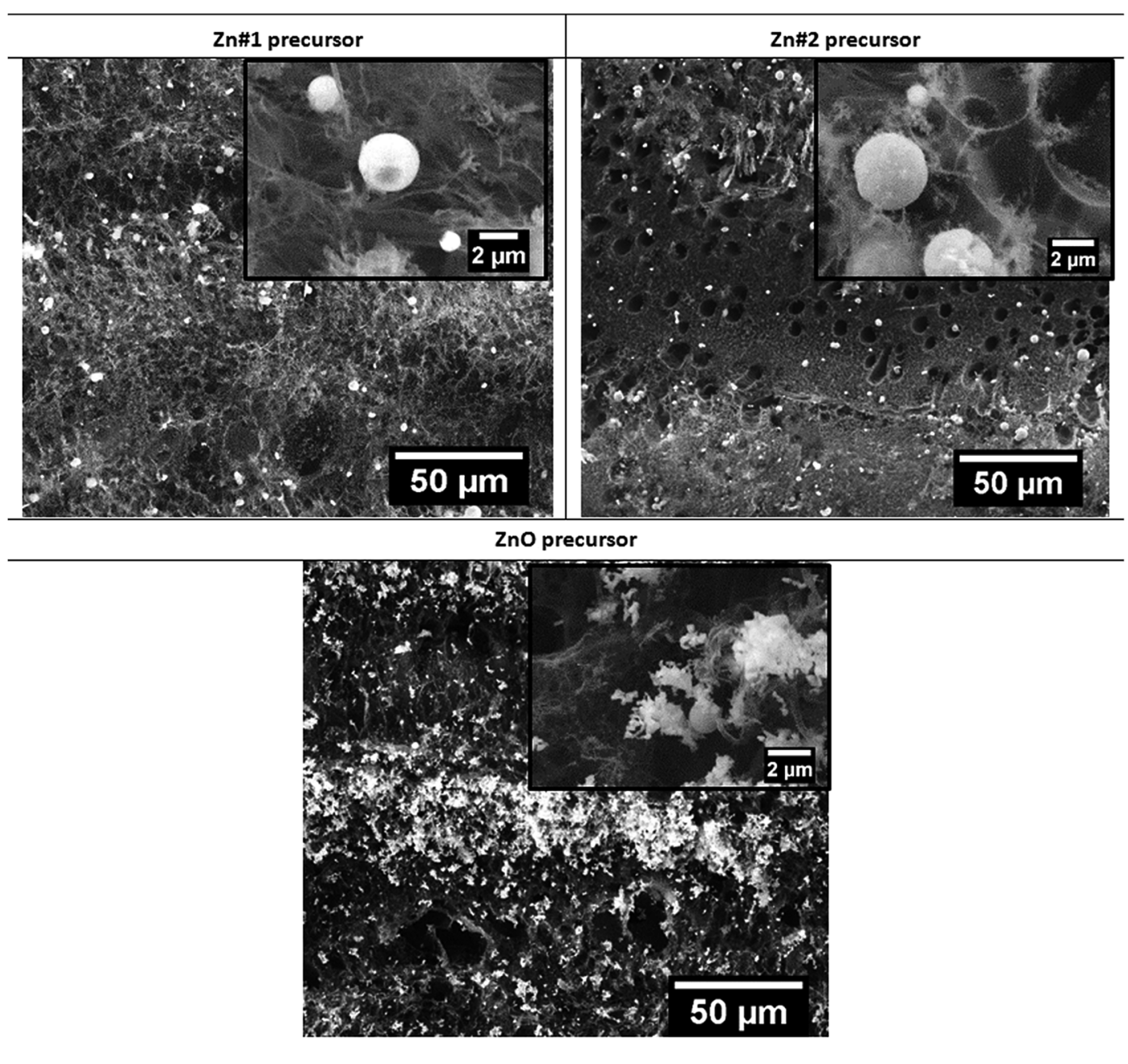

Fig. 4 SEM images of samples from set\#3, using different precursors and similar processing conditions. 
especially concerning the porous distribution of LIG. The sample produced with the $\mathrm{Zn \# 2}$ precursor reveals the presence of larger pores than the ones identified in the $\mathrm{Zn \# 1}$ sample, dispersed in a mesh of much smaller pores. The differences can be attributed to different laser interaction/absorption by the organic compounds that comprise the paste (PVA vs. a mixture of ethanol, terpineol and ethyl cellulose). Additionally, the higher homogeneity of the $\mathrm{Zn}$ particles distribution using the $\mathrm{Zn \# 2}$ precursor, as well as its better adhesion to the Kapton ${ }^{\circledR}$ sheet, may also contribute to the observed differences. Nevertheless, the $\mathrm{ZnO}$ particles seem very similar in these two cases (see also Fig. S3a and $\mathrm{b} \dagger$ ), as attested by their size and shape, and corroborated by the Raman (section 3.2) and PL (section 3.3) results.
Since the yield of $\mathrm{ZnO}$ particles production was relatively low for all the applied processing conditions, a new precursor paste was tested using $\mathrm{ZnO}$ commercial powder instead of metallic Zn. Fig. 4 bottom depicts the SEM image of the resultant composite. As seen in this figure, a larger amount of $\mathrm{ZnO}$ particles is present in this sample, when considering the same laser processing conditions and similar amount of precursor paste. The $\mathrm{ZnO}$ structures tend to accumulate more in the protruded regions of the sample. The higher concentration of $\mathrm{ZnO}$ particles in these regions may also be accounted by the "bombing" effect mentioned earlier. A fast gas release from the polyimide graphenisation may shove the $\mathrm{ZnO}$ to those regions. Additionally, the formed particles do not present the same spherical-like shape as the ones produced from the $\mathrm{Zn}$ pastes. Instead, a more irregular morphology is observed: not only do
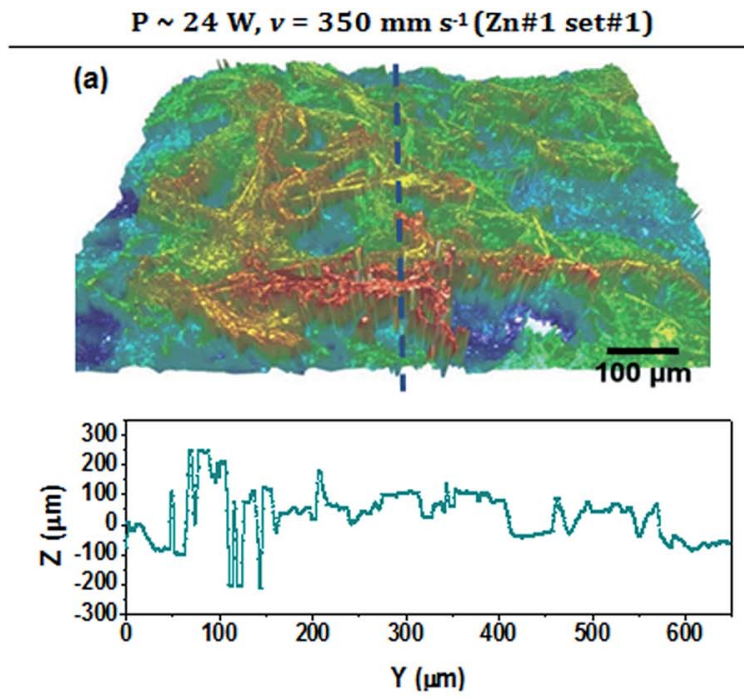

$P \sim 24 \mathrm{~W}, v=200 \mathrm{~mm} \mathrm{~s}^{-1}(\mathrm{Zn \# 1}$ set\#1)

(b)
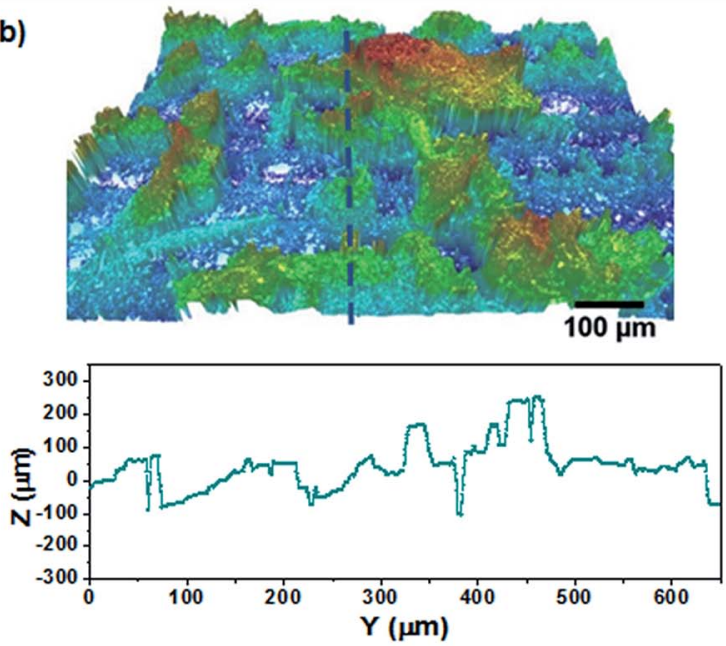

$P \sim 22 \mathrm{~W}, v=150 \mathrm{~mm} \mathrm{~s}^{-1}(\mathrm{ZnO}$ set\#3)
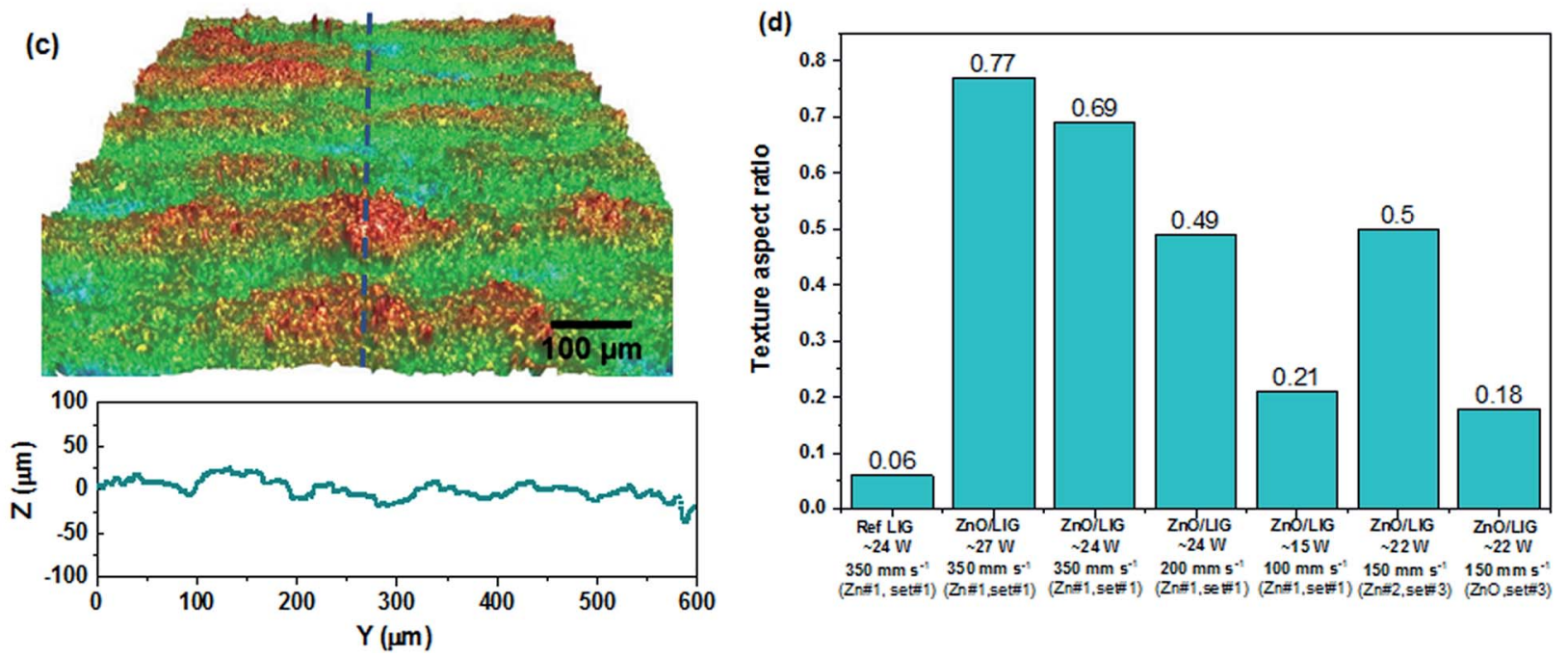

Fig. 5 Optical profilometer images acquired with $20 \times$ magnification and surface profile (taken at the centre of the images - marked line). (a-c) $\mathrm{ZnO/LIG} \mathrm{composites} \mathrm{with} \mathrm{different} \mathrm{laser} \mathrm{processing} \mathrm{conditions.} \mathrm{The} \mathrm{colour} \mathrm{scale} \mathrm{was} \mathrm{defined} \mathrm{from} \mathrm{blue} \mathrm{to} \mathrm{red,} \mathrm{corresponding} \mathrm{to} \mathrm{the} \mathrm{minimum}$ and maximum of the $Z$ values, respectively, and for each individual sample (peak-to-valley full colour scale). (d) Texture aspect ratio (Str) values for the different analysed samples. 
the particles appear to have smaller dimensions (Fig. S3c $\dagger$ ) but also a propensity to form agglomerates. The higher yield observed in this case may be related to the different interaction between the laser and the $\mathrm{ZnO}$ powder particles $v s$. the metallic Zn particles. As previously mentioned, metallic Zn can reflect part of the incident photons, thus reducing the number of photons absorbed. On the other hand, the used wavelength is well absorbed by the ZnO powders, as corroborated by other growth techniques using a similar heating source. ${ }^{58}$ Laser incidence promotes the thermal decomposition of $\mathrm{ZnO}$, leading to the formation of vapours containing the precursors materials. $\mathrm{Zn}$ will react with oxygen from both the atmosphere and the precursor powder, leading to the formation of $\mathrm{ZnO}$ structures that will further be deposited on the surface of the freshly formed LIG.

Fig. 5 depicts 3D optical profilometer images of the selected samples. Their respective surface topographic profiles taken at the central position of the images (blue dashed-lines in the 3D pictures) are also displayed. Moreover, a reference sample corresponding only to LIG was analysed (Fig. S4a†) in order to compare its surface profile and texture aspect ratio with the $\mathrm{ZnO} /$ LIG composite samples for the same laser-writing conditions (specifically the one depicted on Fig. 5a). It was observed that all the samples present alternating valley and hill regions (better identified in Fig. S2a, $\mathrm{c}^{\dagger}$ and 5c), which correpond to the protruded regions mentioned in the SEM analysis. The thickness of these hills roughly increases for higher laser powers, as it was also reported by Luo et al. ${ }^{35}$ The topographical data is obtained from the corresponding $3 \mathrm{D}$ reconstruction of the several individual 2D images, where each individual point corresponds to a certain height value. Given that the surface of the samples comprises a fibre-like structure, it is likely to measure discrete points. As such, a continuous line was only added to the topographical data for the sake of clarity. The texture aspect ratio (Str) parameter was used to spatially evaluate the uniformity of the surface texture of these samples, where a strong directionality of surface structure corresponds to a Str closer to zero (wavy-like) while an Str closer to unit indicates a more disordered texture arrangement. ${ }^{59}$

As it was observed in the SEM micrographs (Fig. 2), the samples prepared with higher power and scanning speed evidence a higher amount of misoriented carbon fibres. In addition, a reduction of the speed from 350 to $200 \mathrm{~mm} \mathrm{~s}^{-1}$ revealed a strong impact on the surface topography of the $\mathrm{ZnO} /$ LIG samples, leading to a more ordered carbon structure. Str values (Fig. 5d) show an increase with laser power and scan speed, therefore revealing more disordered features formed at the surface. By comparing the samples with and without the presence of the $\mathrm{Zn}$ precursor paste and laser-processed under the same conditions, remarkable differences emerge. A more regular surface is observed in the case of the LIG reference sample (denominated Ref LIG in Fig. S4a $\dagger$ ), with a clear alternation between valleys and hills. In fact, and based on previous experiments, these hills are formed by several arranged fibres that arise from the overlapping of part of the laser spot under consecutive scan lines. As previously described, the spot affected zone exceeds the predefined laser line spacing $(0.075$ $\mathrm{mm}$ ) and parts of the sample are thus irradiated twice, i.e. on peripheries of the scanned lines. In line with what has been observed for the samples prepared with $\mathrm{Zn \# 1}$ (please consider $P$ $\sim 24 \mathrm{~W}$ and $v=200 \mathrm{~mm} \mathrm{~s}^{-1}$ for comparison), the sample processed from Zn\#2 (Fig. S4d $\dagger$ ) evidence a high disorder surface. In addition, and from a wider point of view, this sample seems to present larger agglomerates of $\mathrm{Zn} / \mathrm{ZnO}$ at the surface, compared to his counter-part based on $\mathrm{Zn \# 1}$ precursor, and showing also agglomerates of similar dimensions to the ones found in the sample processed under $P \sim 15 \mathrm{~W}$ and $v=100 \mathrm{~mm}$ $\mathrm{s}^{-1}$. This indicates that the $\mathrm{Zn \# 2}$ precursor and the conjugation of laser defocusing along with lower scan rate may result in the formation of larger pores and $\mathrm{ZnO}$ agglomerates. Its texture aspect ratio is comparable with the one obtained for the sample prepared with Zn\#1 and processed under similar conditions, which shows that the laser power sets most of the samples' surface disorder rather than a reduction of the scan rate. Regarding the sample produced from the ZnO-based paste, a much more textured surface is observed, with a clear alternation between hill and valley, similar to what was observed in set\#1 for the sample processed with lower scan speed (Fig. S4c $\dagger$ ). Moreover, a low value for the texture aspect ratio was also attained (Fig. 5d), even lower than the one obtained for the sample processed under $P \sim 15 \mathrm{~W}$ and $v=100 \mathrm{~mm} \mathrm{~s}^{-1}(\mathrm{Zn} \# 1)$ and for the sample processed under the same laser conditions but using the $\mathrm{Zn \# 2}$ precursor. This shows the importance of the light absorption by the precursor's layer to the morphology of the $\mathrm{ZnO} / \mathrm{LIG}$ composite, as well as the dispersion of $\mathrm{ZnO}$ particles on the surface of LIG.

\subsection{Raman spectroscopy}

Representative micro-Raman spectra acquired on different areas of interest of the ZnO/LIG samples are shown in Fig. 6. By taking advantage of the contrast between the different regions, it was possible to characterise areas with a higher amount of ZnO particles ("whiter" regions) and others dominated by the LIG features ("darker" regions). Probing the samples in $\mathrm{ZnO}$ rich regions resulted in the observation of the characteristic Raman active vibrational modes of the $\mathrm{ZnO}$ wurtzite crystalline structure, $\mathrm{A}_{1}, \mathrm{E}_{1}$ and $\mathrm{E}_{2}$, as well as their overtones and combined modes. The "darker" regions exhibited the vibrational modes typically associated with $\mathrm{sp}^{2}$ coordinated carbon, proving that LIG is indeed present in all the samples. As a matter of fact, the vibrational modes of LIG resembles the ones typically observed in reduced graphene oxide ( $\mathrm{rGO})^{\mathbf{6 0}}$ The presence of the welldefined $\mathrm{ZnO}$ vibrational modes in the analysed samples attests the crystallinity of the produced particles. Nevertheless, clear differences are observed between the relative intensities of the different Raman modes, as well as on their full width at half maximum (FWHM). The differences observed in the relative intensity of the vibrational modes may also arise from polarisation effects caused by the different orientations between the $\mathrm{ZnO}$ structures and the incidence wavevector of the laser beam. ${ }^{61-64}$ Additionally, the high intensity of the mode observed in the $2 \mathrm{LO}$ region $\left(2 \mathrm{~A}_{1}(\mathrm{LO}), 2 \mathrm{E}_{1}(\mathrm{LO})\right)$ when compared to the first order phonons can be justified by the resonant excitation 


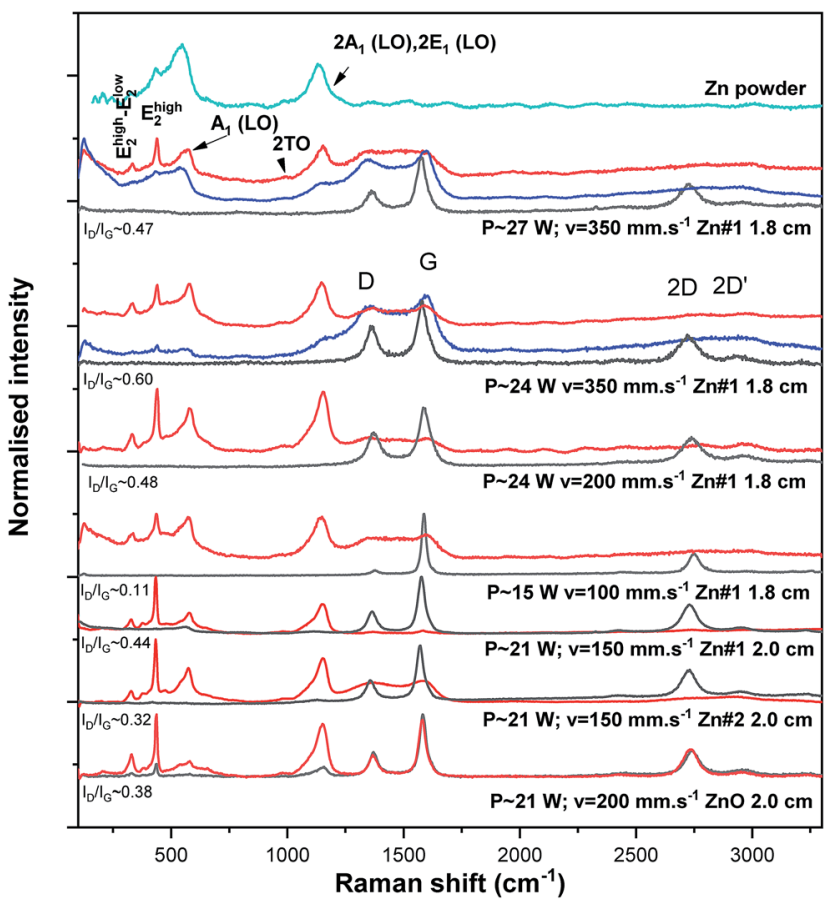

Fig. 6 Raman spectra for selected samples produced with different laser-scribing conditions, obtained in backscattering configuration by exciting the samples with $442 \mathrm{~nm}$ laser line. All spectra were acquired using a ND 0.6 neutral density filter in the excitation. The red lines correspond to regions with higher $\mathrm{ZnO}$ content, while the dark grey lines correspond to regions where LIG predominates. For the samples processed with higher scan speed, the blue lines displayed denote intermediate regions between $\mathrm{ZnO}$-rich and LIG-rich areas. A spectrum of the $\mathrm{Zn}$ powders used as precursor was also added for comparison (light blue line).

conditions, as previously reported in ZnO bulk samples. ${ }^{65}$ Regarding the FWHM, typically sharper peaks are associated with a high degree of crystallinity of the samples, while broader peaks may be accounted by amorphous phases or higher density of defects. For instance, in the case of the samples produced from the $\mathrm{Zn}$-based precursors, the existence of nonstoichiometric $\mathrm{ZnO}_{x}$ phases or residual metallic $\mathrm{Zn}$ with some spontaneously formed native oxide may contribute for the broadening of the Raman lines. In fact, the spectrum acquired on the $\mathrm{Zn}$ powders included in Fig. 6 shows the presence of such native oxide already in the precursor powders, although with broader features than the ones observed for the processed samples. Therefore, the observation of a broad $\mathrm{A}_{1}(\mathrm{LO})$ mode may indeed result from the contribution of $\mathrm{Zn}$ particles that were not fully oxidised during the laser writing process.

As a general trend, defocused conditions seem to lead to sharper $\mathrm{ZnO}$ vibrational modes (see, for instance $\mathrm{E}_{2}^{\text {high }}$ mode) and for the same applied power lower scan rates exhibits sharper peaks, suggesting an improved crystallinity of the produced $\mathrm{ZnO}$ particles in such cases. Regarding the vibrational modes recorded for LIG, the D-band, frequently associated to the $\mathrm{sp}^{2}$ coordinated defective/disordered carbon phases, appears at $\sim 1363-1369 \mathrm{~cm}^{-1}$, while the G-band, related to $\mathrm{C}-\mathrm{C}$ bond stretching in $\mathrm{sp}^{2}$, can be identified at $\sim 1577-1586 \mathrm{~cm}^{-1} \cdot{ }^{66-68}$ The ratio between the peak intensity of these modes, $I_{\mathrm{D}} / I_{\mathrm{G}}$, can be used to measure the relative defect content in the $\mathrm{sp}^{2}$ carbon lattice. ${ }^{67,68}$ In the present case, ratios between 0.11 and 0.60 were obtained, showing a tendency to increase for higher scan speeds. High values of the $I_{\mathrm{D}} / I_{\mathrm{G}}$ indicate the presence of a significant amount of defects, with possibly part of those being originated by oxygen-containing functional groups, suggesting some degree of oxidation in the samples prepared with higher laser power. ${ }^{68}$ Moreover, it was observed that higher $I_{\mathrm{D}} / I_{\mathrm{G}}$ values were obtained for samples with a higher amount of carbon fibres (higher laser powers). This can be inferred, for instance, from the sample produced with $P \sim 15 \mathrm{~W}$, where one can clearly note that when carbon fibres are substantially absent the D-band intensity is extremely low $\left(I_{\mathrm{D}} / I_{\mathrm{G}} \sim 0.11\right)$. Nevertheless, it is also important to take into account the contribution of the high density of graphene's edges for the intensity of the $\mathrm{D}$ band, since they behave as defective regions, thus activating the $\mathrm{D}$ mode. ${ }^{67}$ Besides, the FWHM of these modes is in the order of $52-59 \mathrm{~cm}^{-1}$ and $66-$ $80 \mathrm{~cm}^{-1}$ for G-band and D-band, respectively, which constitutes another indication of the presence of a substantial density of defects and is concomitant with the presence of oxygen-related ones. ${ }^{69,70}$

In fact, the increase in the $I_{\mathrm{D}} / I_{\mathrm{G}}$ ratio seems to have the same tendency as the Str value (excluding the sample prepared under the highest laser power), suggesting a correspondence between the presence of a higher amount of carbon fibres (and thus a higher surface disorder) and the presence of defects. The 2D band appears between $\sim 2724-2740 \mathrm{~cm}^{-1}$, originating from second order zone-boundary phonons..$^{31,71}$ Therefore, the presence of a single and symmetric 2D-band (especially noticeable in the sample prepared with $P \sim 15 \mathrm{~W}$ ), together with the G-band in the presented spectra, clearly indicates the formation of a graphene-based material. ${ }^{47}$ The FWHM of the 2D-band ranges from $\sim 97$ to $104 \mathrm{~cm}^{-1}$ in all the analysed samples, while $I_{2 \mathrm{D}}<I_{\mathrm{G}}$, which are characteristics typically associated to the formation of multi-layer graphene. Furthermore, additional and less intense modes are associated with the $\mathrm{D}+\mathrm{D}^{\prime \prime}, \mathrm{D}+\mathrm{D}^{\prime}$ and $2 \mathrm{D}^{\prime}$ modes. These multi-phonon processes are commonly indicative of defects in graphenebased materials. $^{71}$

It is also important to mention that the absence of LIG Raman features observed when the beam was focused on the $\mathrm{ZnO}$ rich regions may be accounted by the limited penetration depth of the laser beam, probing essentially the ZnO particles and not the LIG underneath. Furthermore, since it was possible to identify broad and overlapped modes associated with the carbon phases, the presence of amorphous carbon in such spectra must be also considered, likely present in the interface between the $\mathrm{ZnO}$ particles and the LIG foam. This suggests that when a $\mathrm{ZnO}$ particle is formed, a small amount of amorphous carbon can also be produced in its vicinity due to the laser interaction with LIG/Kapton ${ }^{\circledR}$ and/or the organic compounds present in the precursor paste. When the sample is probed in a nearby region but away from the $\mathrm{ZnO}$, the spectra display the well-defined LIG characteristic Raman modes. Additionally, intermediate regions were also probed in some samples, as 
displayed in Fig. 6 for the ones processed under higher scan speeds, evidencing the presence of both $\mathrm{ZnO}$ and carbonrelated modes. These regions correspond to the transition areas between the "whiter" ZnO-rich regions and the "darker" LIG-rich ones.

\subsection{Photoluminescence}

As stated in the experimental part, the PL emission was the main property monitored during the optimisation process of the composites' fabrication. As such, all the produced samples were analysed by PL spectroscopy at RT by exciting them with a $325 \mathrm{~nm}(3.81 \mathrm{eV})$ laser beam, which corresponds to an energy above the bandgap of $\mathrm{ZnO}\left(E_{\mathrm{g}} \sim 3.3 \mathrm{eV}\right.$ @ $\left.\mathrm{RT}^{4}\right)$. Fig. 7 depicts the main results obtained for the different sets of conditions tested (see Table 1). Fig. 7a displays the PL spectra for selected samples belonging to the first set (set\#1). In this case, all the analysed
$\mathrm{ZnO} / \mathrm{LIG}$ composites revealed the presence of a broad visible band dominating the spectra, together with the typical near band edge (NBE) emission in the UV region, although with a lower intensity when compared to the visible band. The visible bands identified in these samples present small differences regarding their peak positions, being dependent on the used processing condition. Moreover, the relative intensity between the UV and visible emissions also changes with the synthesis parameters. In all the cases, the broad band extends from the green to the yellow and orange-red spectral range, likely corresponding to an overlap of difference recombination channels. However, these channels present different contributions to the overall broad emission band depending on the processing conditions, even though with a predominance in the orangered spectral region for all the studied samples. These differences result in a slight redshift of the peak position of the broad
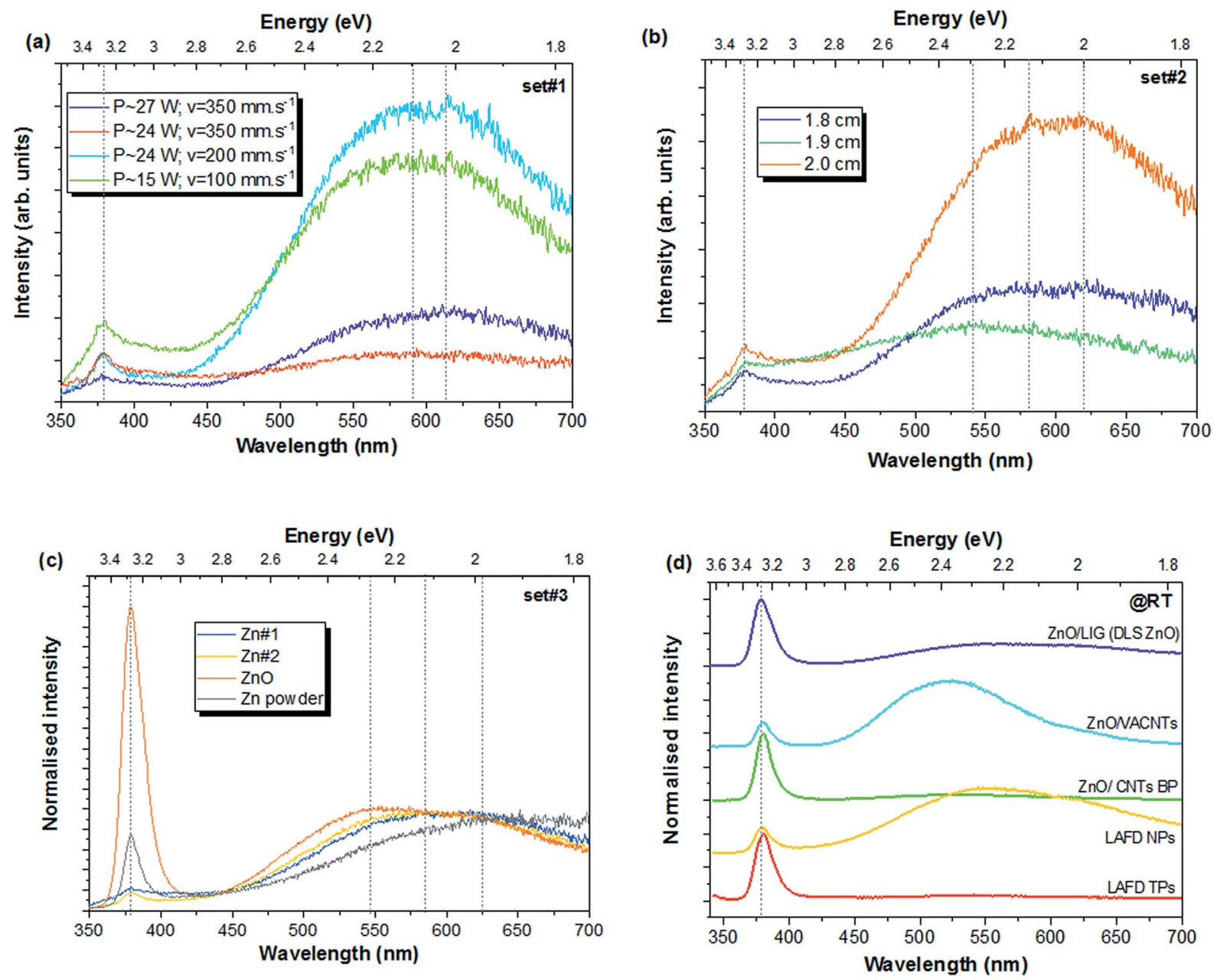

Fig. 7 RT PL spectra obtained by exciting the samples with the $325 \mathrm{~nm}$ laser line: (a) selected samples from set\#1, where the line spacing (0.075 $\mathrm{mm}$ ) and the focused conditions were kept and the Zn\#1 precursor was used; (b) samples from set\#2, where only the distance between laser head and precursors was changed, keeping the remain processing parameters constant ( $\left.d=0.1 \mathrm{~mm} ; v=200 \mathrm{~mm} \mathrm{~s}{ }^{-1} ; P \sim 21 \mathrm{~W}\right)$ and using Zn\#1 precursor; (c) samples from set\#3 comparing the different $\mathrm{ZnO}$ precursors and prepared under the same conditions $(d=0.1 \mathrm{~mm} ; v=150 \mathrm{~mm}$ $\mathrm{s}^{-1} ; \mathrm{P} \sim 22 \mathrm{~W}, d_{\text {laser }}=2 \mathrm{~cm}$ ). A spectrum acquired for the Zn powders was also included for comparison. (d) Comparison between the RT PL spectra of the sample processed by direct-laser writing using the ZnO-based precursor and the LAFD-produced ZnO tetrapods (TPs) and nanoparticles (NPs), as well as other ZnO/carbon composites (ZnO/VACNTs and buckypapers (BPs) formed with a mixture of ZnO TPs and CNTs), produced using the LAFD-ZnO structures. The spectra are vertically displaced for clarity. 
band when higher scan rates and laser power were used. The sample prepared with $P \sim 15 \mathrm{~W}$ and $v=100 \mathrm{~mm} \mathrm{~s}^{-1}$ exhibits the maximum of the band at $\sim 597 \mathrm{~nm}$, while for the sample prepared with $P \sim 27 \mathrm{~W}$, the peak position shifted to $\sim 625 \mathrm{~nm}$. These results show that the formation of the defects originating the orange-red emission is promoted/enhanced when higher laser powers and scan rates are applied. It is worth noting that PL measurements were also performed in the LIG reference samples produced with the same laser-scribing parameters as those of the composites; however, no luminescence signal was detected. The sample prepared with $P \sim 24 \mathrm{~W}$ and $v=200 \mathrm{~mm}$ $\mathrm{s}^{-1}$ was the one that exhibited the highest intensity, followed by the one produced at $P \sim 15 \mathrm{~W}$ and $v=100 \mathrm{~mm} \mathrm{~s}^{-1}$. This seems to indicate that a lower scan speed is beneficial for an improved PL signal, having a predominant effect over the laser power. Moreover, the fact that the highest scan speed used $(350 \mathrm{~mm}$ $\mathrm{s}^{-1}$ ) led to the formation of a considerable amount of carbon fibres, which scattered part of the incident laser beam, may also contribute to the poor PL signal collection. Thus, a proper combination between laser power and scan speed should be met, as low scan speeds compromise the use of higher laser powers, which could result in a damaged sample. These results are in line with what was observed by Raman spectroscopy regarding the broadening of the peaks.

Regarding the NBE recombination, the emission in all the analysed cases of set\#1 is peaked at $\sim 378 \mathrm{~nm}(\sim 3.28 \mathrm{eV})$, corresponding to the free exciton energy position. The broadening of the peak suggests an overlap of other optical centres usually expected in this region, namely transitions associated to surfacerelated defects, as the one identified at $\sim 392 \mathrm{~nm}(\sim 3.16 \mathrm{eV})$ for the samples produced by laser assisted flow deposition (LAFD).$^{58,72}$

The PL results for defocus conditions (set\#2) are depicted in Fig. 7b. It is clearly seen that the focus conditions strongly influence the spectral shape and peak position of the PL emission. Once again, the broad visible bands are likely composed by several emitting centres, whose relative intensity is seen to change with the employed focus conditions. The sample produced with a distance of $2.0 \mathrm{~cm}$ was the one that revealed the highest overall PL intensity and, therefore, this was the value chosen to carrying out the next set of tests (set\#3).

The last set of samples (set\#3) was produced keeping all the processing parameters fixed and only changing the precursors for the $\mathrm{ZnO}$ formation (Fig. 7c). No significant changes were

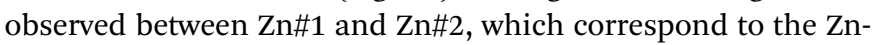
based pastes. Similarly to what was observed in the previous sets of samples, the spectra of these samples are dominated by a broad band peaked in the orange-red spectral region. Conversely, when the precursor based on $\mathrm{ZnO}$ was used, the NBE became the dominant emission, even though a visible broad band is also present in the same spectral range as the previous ones, but exhibiting a higher contribution from the green component(s). This spectral shape resembles the one typically obtained when the LAFD-ZnO is used to form composites (see Fig. 7d). Indeed, those $\mathrm{ZnO}$ precursor powders were the same as the ones used here, while, in the case of the Zn-based precursors, the same Zn metallic powder was used, thus, resulting in the appearance of similar defect-related centres in the PL spectra. Hence, the precursors nature seems to have a strong effect on the PL emission, even taking into account that, in the all the cases, the $\mathrm{Zn} / \mathrm{ZnO}$ powders are embedded in an organic-based layer. The use of different precursor powders is likely to lead to the presence of distinct trace contaminants in the samples, which can give rise to different defects centres and/or distribution of the defects. In fact, it is known that the zinc sources have a strong effect on the properties of the $\mathrm{ZnO}$ structures. ${ }^{73,74}$ For instance, Yu et al. ${ }^{75}$ studied three zinc sources (pure metallic zinc, crystalline ZnO, and $\mathrm{ZnCO}_{3}$ powders) and concluded that different $\mathrm{ZnO}$ structures were formed for each precursor. Moreover, the samples also revealed distinct luminescence features. The authors attributed the observed differences to the yield and constituents/contaminants of the corresponding zinc vapour that is formed during the synthesis process. In the present case, a higher contribution from the deep level defects seems to be promoted by the use of $\mathrm{Zn}$-based precursors. It is important to take into account that, as suggested by the broader peaks in the Raman spectra, the use of $\mathrm{Zn}$ as precursor may result in the presence of some non-stoichiometric $\mathrm{ZnO}_{x}$ phases and/or lattice disorder, as well as some residual $\mathrm{Zn}$, with a native oxide on its surface, which may also play a role in the resultant PL features. In fact, as seen by the PL spectrum recorded in the unprocessed $\mathrm{Zn}$ powders, the NBE recombination and the visible broad band could be identified even prior laser processing. In this case, a higher NBE/visible band intensity was observed when compared to the processed samples using these powders as precursor. Moreover, the visible broad band presents a higher contribution from the red component, being peaked at $\sim 625 \mathrm{~nm}(\sim 1.98 \mathrm{eV})$. These emissions are likely due to the spontaneously formed native oxide already identified by Raman spectroscopy. The differences in the relative intensity of the emission prior and after the laser processing may be related with charge transfer processes between $\mathrm{ZnO}$ and LIG. The decrease in the NBE relative intensity in the presence of LIG could be explained considering interfacial charge transfer between $\mathrm{ZnO}$ and LIG, as reported in other works concerning $\mathrm{ZnO} / \mathrm{rGO}$ composites. ${ }^{76,77}$ According to Kavitha et al.,${ }^{76}$ when the semiconductor is excited with UV light, the photogenerated electrons are likely to transfer to rGO, since the energy position of the conduction band of $\mathrm{ZnO}$ is higher than that of graphene, resulting in a reduction in the recombination of electrons and holes, and thus lower NBE signal. Actually, this seems to be a common feature in other $\mathrm{ZnO} /$ graphene-based composites. $^{76-79}$ However, care must be taken when comparing literature reports on this kind of composites since significant differences may arise depending not only on the type of $\mathrm{ZnO}$ structures used, but also on the graphene synthesis method and its oxidation state. ${ }^{28,76-83}$ In order to highlight the differences that are frequently encountered in distinct $\mathrm{ZnO}$ structures, as well as when they are incorporated into carbon-based composites, Fig. 7d depicts a comparison between the PL spectra of the sample produced by direct-laser writing using the ZnO-based paste and LAFD-produced ZnO structures, as well as other $\mathrm{ZnO} /$ carbon composites prepared with the LAFD-ZnO structures. As can be seen, the luminescence features display distinct 
spectral shapes, even when comparing the samples composed only by ZnO. It is known that the PL signal is strongly depend on several factors, especially on the morphology of the samples and their growth/synthesis methods and conditions (as is evident in the here presented examples of tetrapods and nanoparticles both produced by the LAFD technique). ${ }^{7,58,84}$ Therefore, a comparison between the PL features of different $\mathrm{ZnO} /$ carbon-based composites is not straightforward and needs to take into account several factors. Notwithstanding, the observation of broad luminescence bands peaked in the visible region seems to be a common trend in the present $\mathrm{ZnO} /$ carbon composites, as well as in the ones reported in the literature. Actually, such bands are very common in $\mathrm{ZnO}$ structures and have been attributed to the presence of several types of defects in this semiconductor. ${ }^{85-88}$ Although extensively studied, the nature of these defects remains unclear, accentuated by the fact that different defect centres are known to originate PL emissions in the same spectral regions and even with similar spectral shapes., ${ }^{485}$ The most common defect-related emission is the well-known green luminescence (GL), with a maximum in the range of $2.3-2.5 \mathrm{eV}(\sim 495-540 \mathrm{~nm})$. This band has been associated to defects that range from intrinsic ones, as is the case of oxygen/zinc vacancies $\left(\mathrm{V}_{\mathrm{O}} / \mathrm{V}_{\mathrm{Zn}}\right), \mathrm{Zn}_{\mathrm{O}}$ antisites, interstitial $\mathrm{Zn}$ atoms, transitions from $\mathrm{Zn}$ interstitials to $\mathrm{Zn}$ vacancies, to extrinsic, namely $\mathrm{Cu}$ ions. ${ }^{86,89}$ Nevertheless, there are also some significant evidences that surface-related defects may give rise to a broad luminescence in this spectral region. ${ }^{85,90}$ On the other hand, yellow (YL) and orange-red (RL) bands are less common than the GL and, therefore, less discussed in the literature, although often observed, ${ }^{85,87}$ as in the case of the present $\mathrm{ZnO} / \mathrm{LIG}$ composites. Literature reports regarding the nature of defects emitting in the yellow and orange-red spectral regions have proposed that these emissions may arise from similar deep levels but with different initial states, for instance, between the $\mathrm{ZnO}$ conduction band or shallow donors and deep acceptors. ${ }^{\mathbf{8 5} 8 \mathbf{8}}$ It has been suggested that the orange-red emission is related with excess oxygen, particularly with interstitial oxygen $\left(\mathrm{O}_{\mathrm{i}}\right)$ defects. ${ }^{85,87}$ Typically, intrinsic defects are the most pointed ones for the origin of this emission. ${ }^{85,9-95}$ For instance, Alvi et al. ${ }^{96}$ proposed that the RL is due to the recombination from zinc interstitial to oxygen interstitial defect levels in ZnO. On the other hand, positron annihilation spectroscopy measured in $\mathrm{ZnO}$ bulk samples suggests that the band peaked at $2.1 \mathrm{eV}(\sim 590 \mathrm{~nm})$ correlates with the zinc vacancy density. ${ }^{97}$ Previous works on $\mathrm{ZnO}$ structures prepared by the hydrothermal method ${ }^{84,98}$ have suggested that surface mediated processes (dependent of the synthesis/growth methods) could also contribute to luminescent features in this spectral region. Taking into account the fastness of the laser scribing process, which takes only few seconds per laser stride, such structural defects are likely to be present in here reported samples and their contribution in the observed emission should be considered. In the case of the YL, oxygen interstitial defects are the most commonly proposed origin, although the contribution of some impurities (e.g. Li doping/contamination) have also been suggested. ${ }^{4}$ In fact, Djurišić et al. ${ }^{87}$ reported that both YL and RL were reduced upon annealing in an argon atmosphere, which seems to indicate their correlation with the presence of excess oxygen. However, subsequent annealing in air led to an increase of the RL but not the YL. Indeed, the later has also been related with the presence of $\mathrm{Zn}(\mathrm{OH})_{2}$ at the surface of the ZnO nanostructures, leading to a weak UV and a strong broad yellow emission. ${ }^{85,87}$ This could be a possibility in the present case, since the gases that are generated during the thermal graphenisation of Kapton $\circledast$, as well as the thermal degradation of the organic compounds that comprise the $\mathrm{ZnO}$ precursor pastes, are likely to influence the $\mathrm{ZnO}$ growth and its bulk and surface defect distribution. In this case, $\mathrm{Zn}(\mathrm{OH})_{2}$ and/or - $\mathrm{OH}$ groups can be formed at the surface of $\mathrm{ZnO}$, due either to the polyimide $\left(\mathrm{C}_{22} \mathrm{H}_{10} \mathrm{O}_{5} \mathrm{~N}_{2}\right)$ or the organic compounds that composed the $\mathrm{ZnO}$ precursor, resulting in the presence of recombination processes in the yellow spectral region. ${ }^{85}$ Notwithstanding, as distinct optical centres can be overlapped in the same spectral region and frequently different types of defects are present in the same sample, these multiple recombination channels in the same spectral region give rise to broad emissions bands, which makes it rather difficult to assess the origin of the observed emissions. ${ }^{87,99,100}$

The ratio between the NBE recombination and the deep level emission is frequently used as an indication of the optical quality of the samples. Typically, higher NBE/deep level indicates a high optical quality of the produced $\mathrm{ZnO}$ structures. In addition, this also constitutes a sign of the good structural quality of the samples, since the observation of the free exciton recombination suggests a lower defect concentration. Therefore, the $\mathrm{ZnO}$ formed from the $\mathrm{Zn}$-based precursors is expected to have a higher concentration of defect centres, leading to a higher intensity of the visible bands regarding the NBE emission. Moreover, even after improving the processing conditions of the samples prepared with the Zn-based pastes, the PL signal still presented a rather low intensity when compared to the $\mathrm{ZnO} / \mathrm{LIG}$ composites prepared from the $\mathrm{ZnO}$ paste. This can be partially justified by the higher amount of $\mathrm{ZnO}$ particles on the surface of LIG in the latter case, as seen in the SEM image of Fig. 4 (bottom), as well as by the higher crystalline quality of the produced samples, as seem to be suggested by the Raman spectra (Fig. 6). In this case, the produced composites revealed a PL outcome fairly reproducible, homogenous along the sample and with a good intensity of the signal.

In summary, the laser processing conditions and the used precursors show a noteworthy influence in the defect concentration/distribution of the resultant composites, although some common features were found. Indeed, similar optical centres are expected to be present in the analysed samples, resulting in the broad emission bands. It is also interesting to highlight that, despite the fact that for all the tested conditions, the LIG content predominates over the $\mathrm{ZnO}$ one (even when the ZnO-based precursor was used), the characteristic PL emission of ZnO could be identified at RT and with the visible emission being observed with the naked eye upon ultraviolet laser excitation. Nevertheless, an intense signal is desired for further sensing applications, therefore the sample prepared with the ZnO-based precursor was considered the most adequate for device application purposes and for further electrochemical characterisation. 


\subsection{Electrochemical characterisation}

As mentioned in the experimental section, the electrochemical characterisation was accomplished by performing EIS and CV measurements in the selected samples. In order to get some insight concerning the charge transfer process between $\mathrm{ZnO}$

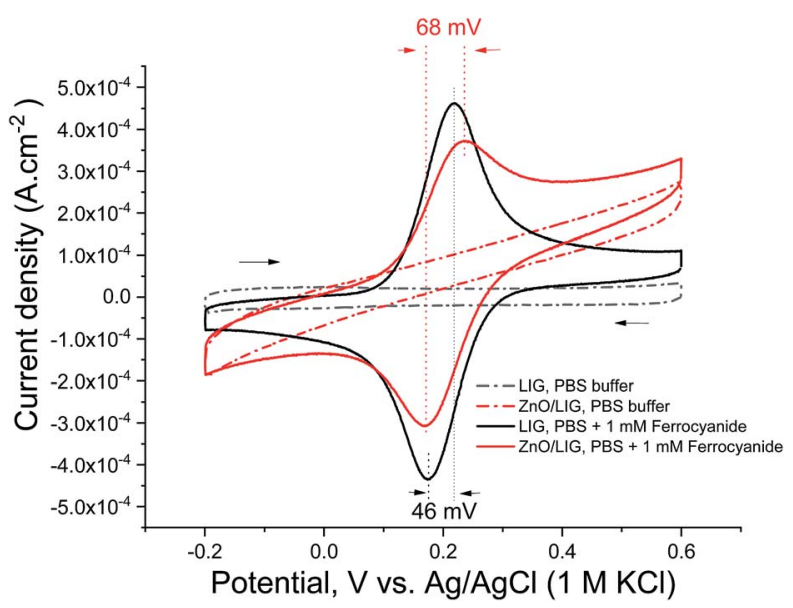

Fig. $8 \mathrm{CVs}$ of LIG reference (black lines) and ZnO/LIG composite (red lines) at $100 \mathrm{mV} \mathrm{s}^{-1}$. The measuring solutions are PBS only (dashed lines) and PBS with $1 \mathrm{mM}$ ferrocyanide (solid lines). particles and LIG, the selected ZnO/LIG sample and electrodes composed only by LIG prepared under the same laser-writing conditions were analysed. Nonetheless, it is important to bear in mind that, since there is no additional $\mathrm{ZnO}$ precursor layer on top of the polyimide sheet, the laser power that reaches the polymer is expected to be somewhat higher than in the case of the composite. Even so, it is fair to assume that this change has no significant influence in the resulted analysis, allowing to compare the data for both samples.

The CVs in PBS of both LIG and ZnO/LIG electrodes (Fig. 8) denote a symmetric, quasi-rectangular shape, even at relatively high scan rates of $100 \mathrm{mV} \mathrm{s}{ }^{-1}$, which is a good indication of their capacitive nature. Capacitive currents and the area inside the CVs are enhanced for the $\mathrm{ZnO} / \mathrm{LIG}$ electrode, which clearly underline the augmented capacitance due to the $\mathrm{ZnO}$ particles. This correlates well with that observed in several reports in the literature. ${ }^{101,102}$

When $1 \mathrm{mM}$ ferrocyanide is added to the electrolyte, welldefined waves of redox activity of diffusing species appear in both CVs (solid lines in Fig. 8). In fact, the CV of the LIG sample resembles that of a reversible redox pair. The anodic-to-cathodic peak separation is only $46 \mathrm{mV}$, which is below the theoretical minimum of $\sim 57 \mathrm{mV}^{\mathbf{1 0 3}}$ for a reversible one-electron redox process based on diffusing species. This could be due to partial and weak adsorption of ferro/ferricyanide ions to LIG surface,

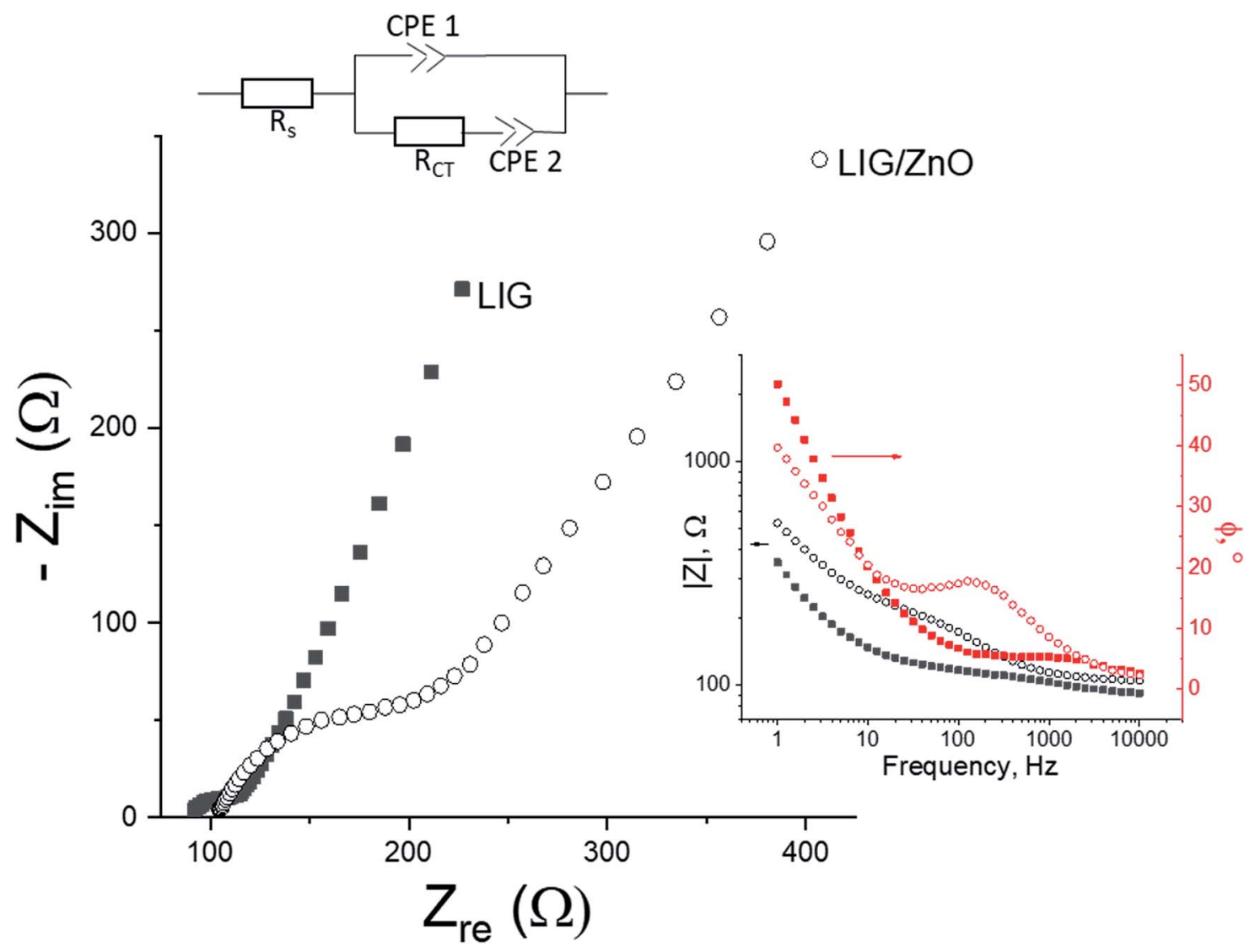

Fig. 9 EIS Nyquist plot of LIG reference (solid squares) and ZnO/LIG composite (open circles) using an AC perturbation of $5 \mathrm{mV}$ upon the open circuit potential. The measuring solution is $1 \mathrm{mM}$ ferro/ferricyanide in PBS. Insets: corresponding Bode plots and the equivalent circuit used to model the cell are also shown. 
which is known to influence the peak position, whereas for strongly adsorbed species no peak-to-peak separation is often observed. Also, there are no additional peaks, which would appear in the case of strong adsorption, arising from the different activation energies for oxidation of strongly adsorbed and diffusing ferrocyanide ions. Moreover, the fact that the adsorption is weak and reversible is confirmed by the absence of the faradaic peaks after rinsing and re-measuring the $\mathrm{CV}$ response in PBS buffer only. Noticeably, the peak-to-peak separation is increased to $68 \mathrm{mV}$ for the $\mathrm{ZnO} / \mathrm{LIG}$ sample, accompanied by lower intensity faradaic peak currents. This indicates that charge transfer between LIG and ZnO microparticles occurs and the $\mathrm{ZnO}$ phase participates in the faradaic process, also inducing some degree of irreversibility to it.

The EIS Nyquist and Bode plots of the same samples are shown in Fig. 9. The spectra of both sample types are well-fitted by the mixed kinetic-diffusion equivalent circuit shown in Fig. 9, where $R_{\mathrm{S}}$ is the series ohmic resistance, $R_{\mathrm{CT}}$ the charge transfer resistance and CPE 1 and CPE 2 are constant phase elements modelling the (non-ideal) double layer capacitance and ferro/ ferricyanide diffusion, respectively. The plateaus of the impedance Bode plot were used to initialise the values of the fittings.

The LIG reference shows only a slight modulation due to $R_{\mathrm{CT}}$ at higher frequencies, before diffusion takes over the impedimetric response at lower frequencies. This resistance appears in the form of a small, depressed semi-circle in the Nyquist plot (plateaus and peaks in the Bode impedance and phase plots, respectively). On the contrary, that modulation is much clearer for the ZnO/LIG. A four-fold increase in $R_{\mathrm{CT}}$ from $\sim 30$ to $\sim 120 \Omega$ is inferred when $\mathrm{ZnO}$ particles are present, in line with the findings from the CV measurements.

\section{Conclusions}

In this work we have successfully synthesised $\mathrm{ZnO}$ decorated LIG samples via a direct-laser scribing approach, using a $\mathrm{CO}_{2}$ laser as the irradiation source and a commercial polymer (Kapton ${ }^{\circledR}$ ) sheet covered with $\mathrm{ZnO}$ precursor for simultaneous production of $\mathrm{ZnO}$ and LIG. The $\mathrm{ZnO} / \mathrm{LIG}$ composites produced through this method and using Zn-based precursors comprise spherical-shaped aggregates of $\mathrm{ZnO}$ microparticles randomly distributed at the LIG surface, while the ones produced from a ZnO-based precursor paste exhibit a more irregular shape. Moreover, even using the same amount of powder in the precursor paste, different precursors lead to different yields of the ZnO particles' production, with the ZnO-based precursor presenting the highest yield. Different combinations of processing parameters were employed and it was observed that the surface morphology was strongly dependent on the chosen conditions. For instance, it was seen that the highest laser powers and scanning speeds resulted in a higher amount of ZnO-decorated randomly oriented carbon fibres, while for lower values of both parameters $\left(P \leq 24 \mathrm{~W}\right.$ and $\left.v \leq 200 \mathrm{~mm} \mathrm{~s}^{-1}\right)$ it led to a reduction in the formation of the carbon fibres and a highly porous 3D foam-like LIG structure was obtained. Raman spectroscopy revealed the crystallinity of the formed $\mathrm{ZnO}$ particles, whose RT luminescence is dominated by broad visible bands in the case of the samples obtained from $\mathrm{Zn \# 1}$ and $\mathrm{Zn \# 2}$ precursors, also exhibiting the presence of the NBE emission in the UV, even when low laser powers were employed. The NBE/ visible emission ratio was altered when the ZnO-based precursor was used, evidencing a higher NBE intensity.

Electrochemical characterisation revealed an increase in the capacitance of the composite samples, when compared to the LIG reference, due to the presence of the $\mathrm{ZnO}$ particles. Moreover, both CV and EIS measurements point to the presence of charge transfer processes between LIG and ZnO microparticles.

This study has indeed shown the possibility of producing $\mathrm{ZnO} /$ LIG composites that can be easily patterned in a time- and cost-effective scalable approach. The simplicity of the fabrication process and the interesting structural, optical and electrochemical properties that result from the combination of $\mathrm{ZnO}$ with graphene makes $\mathrm{ZnO} / \mathrm{LIG}$ composites good candidates to be employed in flexible and miniaturised devices in a wide range of applications, namely in the sensing field.

\section{Conflicts of interest}

There are no conflicts to declare.

\section{Acknowledgements}

The authors acknowledge financial support from FEDER funds through the COMPETE 2020 Programme and National Funds through FCT - Portuguese Foundation for Science and Technology under the projects UID/CTM/50025/2019 and POCI-01-0145FEDER-028755. A. F. Carvalho acknowledges the PhD grant DAEPHYS-FCT PD/BD/114063/2015, and the funding from "Programa de Estímulo à Investigação 2016" from Fundação Calouste Gulbenkian. Acknowledgements are also due to Doctor Filipe Oliveira from CICECO for the access of the optical profiler equipment.

\section{Notes and references}

1 S. S. Bhat, A. Qurashi and F. A. Khanday, TrAC, Trends Anal. Chem., 2017, 86, 1-13.

2 L. Zheng, Y. Wan, P. Qi, Y. Sun, D. Zhang and L. Yu, Talanta, 2017, 167, 600-606.

3 X. Dong, Y. Cao, J. Wang, M. B. Chan-Park, L. Wang, W. Huang and P. Chen, RSC Adv., 2012, 2, 4364.

4 U. Özgür, Y. I. Alivov, C. Liu, A. Teke, M. A. Reshchikov, S. Doğan, V. Avrutin, S.-J. Cho and H. Morkoç, J. Appl. Phys., 2005, 98, 041301.

5 Y. K. Mishra and R. Adelung, Mater. Today, 2017, 21, 631651.

6 O. Lupan, V. Postica, J. Gröttrup, A. K. Mishra, N. H. de Leeuw, J. F. C. Carreira, J. Rodrigues, N. Ben Sedrine, M. R. Correia, T. Monteiro, V. Cretu, I. Tiginyanu, D. Smazna, Y. K. Mishra and R. Adelung, ACS Appl. Mater. Interfaces, 2017, 9, 4084-4099.

7 V. Postica, J. Gröttrup, R. Adelung, O. Lupan, A. K. Mishra, N. H. de Leeuw, N. Ababii, J. F. C. Carreira, J. Rodrigues, N. Ben Sedrine, M. R. Correia, T. Monteiro, V. Sontea and Y. K. Mishra, Adv. Funct. Mater., 2017, 27, 1604676. 
8 J. Rodrigues, S. M. C. Miranda, A. J. S. Fernandes, E. Nogales, L. C. Alves, E. Alves, G. Tourbot, T. Auzelle, B. Daudin, B. Méndez, T. Trindade, K. Lorenz, F. M. Costa and T. Monteiro, Phys. Status Solidi C, 2013, 10, 667-672.

9 B. K. Gupta, V. Grover, G. Gupta and V. Shanker, Nanotechnology, 2010, 21, 475701.

10 I. Sameera, R. Bhatia and V. Prasad, Phys. B, 2010, 405, 1709-1714.

11 T. Kavitha, A. I. Gopalan, K.-P. Lee and S.-Y. Park, Carbon, 2012, 50, 2994-3000.

12 N. A. Noor Azmy, A. A. A. Bakar, N. Arsad, S. Idris, A. R. Mohmad and A. Abdul Hamid, Appl. Surf. Sci., 2017, 392, 1134-1143.

13 G.-Y. Zeng, K.-S. Nian and K.-Y. Lee, Diamond Relat. Mater., 2010, 19, 1457-1460.

14 J. Chen, C. Li, D. W. Zhao, W. Lei, Y. Zhang, M. T. Cole, D. P. Chu, B. P. Wang, Y. P. Cui, X. W. Sun and W. I. Milne, Electrochem. Commun., 2010, 12, 1432-1435.

15 H. Moussa, E. Girot, K. Mozet, H. Alem, G. Medjahdi and R. Schneider, Appl. Catal., B, 2016, 185, 11-21.

16 X. Li, Z. Wang, Y. Qiu, Q. Pan and P. Hu, J. Alloys Compd., 2015, 620, 31-37.

17 J. Rodrigues, D. Mata, A. J. S. Fernandes, M. A. Neto, R. F. Silva, T. Monteiro and F. M. Costa, Acta Mater., 2012, 60, 5143-5150.

18 J. Rodrigues, D. Mata, A. Pimentel, D. Nunes, R. Martins, E. Fortunato, A. J. Neves, T. Monteiro and F. M. Costa, J. Mater. Sci. Eng. B, 2015, 195, 38-44.

19 O. Lupan, F. Schütt, V. Postica, D. Smazna, Y. K. Mishra and R. Adelung, Sci. Rep., 2017, 7, 14715.

20 Y. Zhao, W. Li, L. Pan, D. Zhai, Y. Wang and L. Li, Sci. Rep., 2016, 6, 32327.

21 F. Liu, Y. Zhang, J. Yu, S. Wang, S. Ge and X. Song, Biosens. Bioelectron., 2014, 51, 413-420.

22 S. Kumar, W. Ahlawat, R. Kumar and N. Dilbaghi, Biosens. Bioelectron., 2015, 70, 498-503.

23 P. Norouzi, H. Ganjali, B. Larijani, M. R. Ganjali, F. Faridbod and H. A. Zamani, Int. J. Electrochem. Sci., 2011, 6, 5189-5199.

24 D. Smazna, J. Rodrigues, S. Shree, V. Postica, G. Neubüser, A. F. Martins, N. Ben Sedrine, N. K. Jena, L. Siebert, F. Schütt, O. Lupan, R. Ahuja, M. R. P. Correia, T. Monteiro, L. Kienle, Y. Yang, Y. K. Mishra and R. Adelung, Nanoscale, 2018, 10, 10050-10062.

25 S. Palanisamy and S. Cheemalapati, Int. J. Electrochem. Sci., 2012, 7, 8394-8407.

26 S. S. Low, M. T. T. Tan, H.-S. Loh, P. S. Khiew and W. S. Chiu, Anal. Chim. Acta, 2016, 903, 131-141.

27 F. Liu, W. Deng, Y. Zhang, S. Ge, J. Yu and X. Song, Anal. Chim. Acta, 2014, 818, 46-53.

28 E. Rokhsat and O. Akhavan, Appl. Surf. Sci., 2016, 371, 590595.

29 D. Eder, Chem. Rev., 2010, 110, 1348-1385.

30 M.-M. Lu, W.-Q. Cao, H.-L. Shi, X.-Y. Fang, J. Yang, Z.-L. Hou, H.-B. Jin, W.-Z. Wang, J. Yuan and M.-S. Cao, J. Mater. Chem. A, 2014, 2, 10540.
31 J. Lin, Z. Peng, Y. Liu, F. Ruiz-Zepeda, R. Ye, E. L. G. Samuel, M. J. Yacaman, B. I. Yakobson and J. M. Tour, Nat. Commun., 2014, 5, 5714.

32 A. Lamberti, F. Perrucci, M. Caprioli, M. Serrapede, M. Fontana, S. Bianco, S. Ferrero and E. Tresso, Nanotechnology, 2017, 28, 174002.

33 F. Clerici, M. Fontana, S. Bianco, M. Serrapede, F. Perrucci, S. Ferrero, E. Tresso and A. Lamberti, ACS Appl. Mater. Interfaces, 2016, 8, 10459-10465.

34 R. Ye, Z. Peng, T. Wang, Y. Xu, J. Zhang, Y. Li, L. G. Nilewski, J. Lin and J. M. Tour, ACS Nano, 2015, 9, 9244-9251.

35 S. Luo, P. T. Hoang and T. Liu, Carbon, 2016, 96, 522-531. 36 Y. Li, D. X. Luong, J. Zhang, Y. R. Tarkunde, C. Kittrell, F. Sargunaraj, Y. Ji, C. J. Arnusch and J. M. Tour, Adv. Mater., 2017, 29, 1700496.

37 L. Li, J. Zhang, Z. Peng, Y. Li, C. Gao, Y. Ji, R. Ye, N. D. Kim, Q. Zhong, Y. Yang, H. Fei, G. Ruan and J. M. Tour, Adv. Mater., 2016, 28, 838-845.

38 S. P. Singh, Y. Li, A. Be'er, Y. Oren, J. M. Tour and C. J. Arnusch, ACS Appl. Mater. Interfaces, 2017, 9, 18238-18247.

39 M. Bayati, H. Peng, H. Deng, J. Lin and M. Fidalgo, MRS Adv., 2017, 2, 2489-2495.

40 J. Zhang, M. Ren, L. Wang, Y. Li, B. I. Yakobson and J. M. Tour, Adv. Mater., 2018, 30, 1707319.

41 R. Ye, D. K. James and J. M. Tour, Acc. Chem. Res., 2018, 51, 1609-1620.

42 L. X. Duy, Z. Peng, Y. Li, J. Zhang, Y. Ji and J. M. Tour, Carbon, 2018, 126, 472-479.

43 R. Ye, D. K. James and J. M. Tour, Adv. Mater., 2018, 30, 1803621.

44 D. X. Luong, A. K. Subramanian, G. A. L. Silva, J. Yoon, S. Cofer, K. Yang, P. S. Owuor, T. Wang, Z. Wang, J. Lou, P. M. Ajayan and J. M. Tour, Adv. Mater., 2018, 30, 1707416.

45 W. Song, J. Zhu, B. Gan, S. Zhao, H. Wang, C. Li and J. Wang, Small, 2018, 14, 1702249.

46 F. Wang, K. Wang, B. Zheng, X. Dong, X. Mei, J. Lv, W. Duan and W. Wang, Mater. Technol., 2018, 33, 340-356.

47 Y. Chyan, R. Ye, Y. Li, S. P. Singh, C. J. Arnusch and J. M. Tour, ACS Nano, 2018, 12, 2176-2183.

48 A. F. Carvalho, A. J. S. Fernandes, C. Leitão, J. Deuermeier, A. C. Marques, R. Martins, E. Fortunato and F. M. Costa, Adv. Funct. Mater., 2018, 28, 1805271.

49 J. Zhang, M. Ren, Y. Li and J. M. Tour, ACS Energy Lett., 2018, 3, 677-683.

50 M. Inagaki, S. Harada, T. Sato, T. Nakajima, Y. Horino and K. Morita, Carbon, 1989, 27, 253-257.

51 M. Inagaki, N. Ohta and Y. Hishiyama, Carbon, 2013, 61, 121.

52 Z. W. Li, W. Gao and R. J. Reeves, Surf. Coat. Technol., 2005, 198, 319-323.

53 A. Sekar, S. H. Kim, A. Umar and Y. B. Hahn, J. Cryst. Growth, 2005, 277, 471-478.

54 H. J. Fan, R. Scholz, F. M. Kolb and M. Zacharias, Appl. Phys. Lett., 2004, 85, 4142-4144.

55 Y. Qiu and S. Yang, Adv. Funct. Mater., 2007, 17, 1345-1352.

56 Y. Tsuchiya and K. Sumi, J. Polym. Sci. A-1 Polym. Chem., 1969, 7, 3151-3158. 
57 Z. Peng and L. X. Kong, Polym. Degrad. Stab., 2007, 92, 10611071.

58 J. Rodrigues, A. J. Fernandes, T. Monteiro and F. Costa, CrystEngComm, 2019, 21, 1071-1090.

59 Development of a basis for 3D surface roughness standards, Webpage from Cent. Ultra Precis. Technol. Univ. Huddersf.,1998.

60 X. Díez-Betriu, S. Álvarez-García, C. Botas, P. Álvarez, J. Sánchez-Marcos, C. Prieto, R. Menéndez and A. de Andrés, J. Mater. Chem. C, 2013, 1, 6905.

61 J. Rodrigues, A. J. S. Fernandes, D. Mata, T. Holz, R. G. Carvalho, R. Fath Allah, T. Ben, D. Gonzalez, R. F. Silva, A. F. da Cunha, M. R. Correia, L. C. Alves, K. Lorenz, A. J. Neves, F. M. Costa and T. Monteiro, in SPIE OPTO, ed. F. H. Teherani, D. C. Look and D. J. Rogers, International Society for Optics and Photonics, 2014, p. 89871F.

62 R. Cuscó, E. Alarcón-Lladó, J. Ibáñez, L. Artús, J. Jiménez, B. Wang and M. Callahan, Phys. Rev. B, 2007, 75, 165202.

63 L. Bergman, X.-B. Chen, J. Huso, J. L. Morrison and H. Hoeck, J. Appl. Phys., 2005, 98, 093507.

64 T. Sander, S. Eisermann, B. K. Meyer and P. J. Klar, Phys. Rev. B, 2012, 85, 165208.

65 J. M. Calleja and M. Cardona, Phys. Rev. B: Solid State, 1977, 16, 3753-3761.

66 A. C. Ferrari and D. M. Basko, Nat. Nanotechnol., 2013, 8, 235-246.

67 A. C. Ferrari, Solid State Commun., 2007, 143, 47-57.

68 A. V. Naumov, in Graphene Oxide, John Wiley \& Sons, Ltd, Chichester, UK, 2016, pp. 147-174.

69 E. H. Martins Ferreira, M. V. O. Moutinho, F. Stavale, M. M. Lucchese, R. B. Capaz, C. A. Achete and A. Jorio, Phys. Rev. B, 2010, 82, 125429.

70 A. M. Dimiev S. Eigler, Graphene oxide: fundamentals and applications, John Wiley \& Sons, Ltd, 2016.

71 L. G. Cançado, A. Jorio, E. H. M. Ferreira, F. Stavale, C. A. Achete, R. B. Capaz, M. V. O. Moutinho, A. Lombardo, T. S. Kulmala and A. C. Ferrari, Nano Lett., 2011, 11, 3190-3196.

72 J. Rodrigues, T. Holz, R. Fath Allah, D. Gonzalez, T. Ben, M. R. Correira, T. Monteiro and F. M. Costa, Sci. Rep., 2015, 5, 10783.

73 P.-C. Chang, Z. Fan, D. Wang, W.-Y. Tseng, W.-A. Chiou, J. Hong and J. G. Lu, Chem. Mater., 2004, 16, 5133-5137.

74 A. Kołodziejczak-Radzimska and T. Jesionowski, Materials, 2014, 7, 2833-2881.

75 W. D. Yu, X. M. Li, X. D. Gao, P. S. Qiu, W. X. Cheng and A. L. Ding, Appl. Phys. A, 2004, 79, 453-456.

76 M. K. Kavitha, S. C. Pillai, P. Gopinath and H. John, J. Environ. Chem. Eng., 2015, 3, 1194-1199.

77 Y.-C. Chen, K. Katsumata, Y.-H. Chiu, K. Okada, N. Matsushita and Y.-J. Hsu, Appl. Catal., A, 2015, 490, 1-9.

78 S. Ameen, M. Shaheer Akhtar, H.-K. Seo and H. Shik Shin, Mater. Lett., 2013, 100, 261-265.

79 G. Singh, A. Choudhary, D. Haranath, A. G. Joshi, N. Singh, S. Singh and R. Pasricha, Carbon, 2012, 50, 385-394.

80 J. Liu, Z. Zhang, Y. Lv, J. Yan, J. Yun, W. Zhao, L. Kou and C. Zhai, Composites, Part B, 2016, 99, 366-372.
81 K. Kim, S. Min Lee, Y. Seon Do, S. Il Ahn and K. Cheol Choi, J. Appl. Phys., 2013, 114, 074903.

82 G. Khurana, S. Sahoo, S. K. Barik and R. S. Katiyar, J. Alloys Compd., 2013, 578, 257-260.

83 R. K. Biroju, N. Tilak, G. Rajender, S. Dhara and P. K. Giri, Nanotechnology, 2015, 26, 145601.

84 A. Pimentel, J. Rodrigues, P. Duarte, D. Nunes, F. M. Costa, T. Monteiro, R. Martins and E. Fortunato, J. Mater. Sci., 2015, 50, 5777-5787.

85 A. B. Djurišić, Y. H. Leung, K. H. Tam, Y. F. Hsu, L. Ding, W. K. Ge, Y. C. Zhong, K. S. Wong, W. K. Chan, H. L. Tam, K. W. Cheah, W. M. Kwok and D. L. Phillips, Nanotechnology, 2007, 18, 095702.

86 A. F. Kohan, G. Ceder, D. Morgan and C. G. Van De Walle, Phys. Rev. B, 2000, 61, 19-27.

87 A. B. Djurišić, Y. H. Leung, K. H. Tam, L. Ding, W. K. Ge, H. Y. Chen and S. Gwo, Appl. Phys. Lett., 2006, 88, 103107.

88 M. A. Reshchikov, H. Morkoç, B. Nemeth, J. Nause, J. Xie, B. Hertog and A. Osinsky, Phys. B, 2007, 401-402, 358-361.

89 C. Jagadish and S. J. Pearton, Zinc oxide bulk, thin films and nanostructures: processing, properties and applications, Elsevier, 2006.

90 D. Li, Y. H. Leung, A. B. Djurišić, Z. T. Liu, M. H. Xie, S. L. Shi, S. J. Xu and W. K. Chan, Appl. Phys. Lett., 2004, 85, 1601-1603.

91 K. H. Tam, C. K. Cheung, Y. H. Leung, A. B. Djurišić, C. C. Ling, C. D. Beling, S. Fung, W. M. Kwok, W. K. Chan, D. L. Phillips, L. Ding and W. K. Ge, J. Phys. Chem. B, 2006, 110, 20865-20871.

92 R. B. M. Cross, M. M. De Souza and E. M. S. Narayanan, Nanotechnology, 2005, 16, 2188-2192.

93 S. A. Studenikin, N. Golego and M. Cocivera, J. Appl. Phys., 1998, 84, 2287.

94 M. Gomi, N. Oohira, K. Ozaki and M. Koyano, Jpn. J. Appl. Phys., 2003, 42, 481-485.

95 H. J. Fan, R. Scholz, F. M. Kolb, M. Zacharias, U. Gosele, F. Heyroth, C. Eisenschmidt, T. Hempel and J. Christen, Appl. Phys. A, 2004, 79, 1895-1900.

96 N. H. Alvi, K. ul Hasan, O. Nur and M. Willander, Nanoscale Res. Lett., 2011, 6, 130.

97 L. J. Brillson, Y. Dong, F. Tuomisto, B. G. Svensson, A. Y. Kuznetsov, D. Doutt, H. L. Mosbacker, G. Cantwell, J. Zhang, J. J. Song, Z.-Q. Fang and D. C. Look, Phys. Status Solidi, 2012, 9, 1566-1569.

98 A. Pimentel, D. Nunes, P. Duarte, J. Rodrigues, F. M. Costa, T. Monteiro, R. Martins and E. Fortunato, J. Phys. Chem. C, 2014, 118, 14629-14639.

99 H. Zeng, G. Duan, Y. Li, S. Yang, X. Xu and W. Cai, Adv. Funct. Mater., 2010, 20, 561-572.

100 L. J. Brillson and Y. Lu, J. Appl. Phys., 2011, 109, 121301.

101 Y. Wang, X. Xiao, H. Xue and H. Pang, ChemistrySelect, 2018, 3, 550-565.

102 M. Saranya, R. Ramachandran and F. Wang, Journal of Science: Advanced Materials and Devices, 2016, 1, 454-460.

103 A. J. Bard and L. R. Faulkner, Electrochemical methods: Fundamentals and Applications, John Wiley \& Sons, Inc., 2nd edn, 2001. 